\title{
Inovação e bricolagem sociais com intermediação após um desastre em Córrego d’Antas
}

\author{
Edmilson Lima 1 \\ Reed Nelson ${ }^{2}$ \\ 1 Universidade Nove de Julho / Programa de Pós-Graduação em Administração, São Paulo / SP - Brasil \\ 2 University of Louisiana at Lafayette / B.I. Moody III College of Business Administration, Louisiana - Estados Unidos
}

Estudamos como uma comunidade brasileira respondeu a um desastre com várias inovações sociais (IS) propiciadas por bricolagem social e intermediação com stakeholders. O artigo busca explicar tais processos e sua inter-relação. A abordagem metodológica foi majoritariamente indutiva, utilizando entrevistas abertas e semiestruturadas e análise documental, além da experiência do autor principal, que residiu na localidade antes, durante e após o desastre. Nossos resultados sugerem que este abalou o equilíbrio social da comunidade de diversas maneiras e desencadeou ondas subsequentes de IS ligadas a bricolagem social e intermediação, as quais se amenizaram parcialmente ao longo do tempo. A originalidade e o valor do artigo derivam do contexto único e negligenciado de recuperação pós-desastre em um país emergente e da aplicação de avanços na conceitualização da intermediação e de sua relação com a bricolagem social e a IS.

Palavras-chave: inovação social; bricolagem social; intermediação; stakeholders.

\section{Innovación y bricolaje sociales con intermediación después de un desastre en Córrego d'Antas}

Estudiamos cómo una comunidad brasileña respondió a un desastre con varias innovaciones sociales (IS) propiciadas por el bricolaje social y la intermediación con stakeholders. El artículo busca explicar tales procesos y su interrelación. El enfoque metodológico fue principalmente inductivo, utilizando entrevistas abiertas y semiestructuradas y análisis documental, además de la experiencia del autor principal que residió en la localidad antes, durante y después del desastre. Nuestros resultados sugieren que dicho acontecimiento afectó el equilibrio social de la comunidad de diversas maneras y desencadenó oleadas subsiguientes de IS relacionadas con el bricolaje social y la intermediación que se atenuaron parcialmente con el tiempo. La originalidad y el valor del artículo derivan del contexto único y de abandono de recuperación posdesastre en un país emergente y de la aplicación de avances en la conceptualización de la intermediación y de su relación con el bricolaje social y la IS.

Palabras clave: innovación social; bricolaje social; intermediación; stakeholders.

\section{Social innovation, social bricolage, and brokerage after a disaster in Córrego d'Antas}

We studied how a Brazilian community responded to a disaster using social innovations (SI) developed based on social bricolage and brokerage with stakeholders. The paper seeks to explain these processes and their interrelation. The methodological approach was primarily inductive, using semi-structured and open-ended interviews, document analysis, and the residential experience of the senior author before, during, and after the disaster. Our results suggest that the disaster upset the social balance of the community in several ways and triggered waves of subsequent SI related to social bricolage and brokerage that faded somewhat over time. Originality and value of the paper derive both from the unique and neglected context of post-disaster recuperation in a developing country and from the application of advances in the conceptualization of brokerage and its relation to social bricolage and SI.

Keywords: social innovation; social bricolage; brokerage; stakeholders. 


\section{INTRODUÇÃO}

As inovações sociais (IS) são iniciativas coletivas que tratam necessidades sociais, aprimoram relações humanas ou melhoram a qualidade de vida das pessoas (Ettorre, Bellantuono, Scozzi \& Pontrandolfo, 2014). Embora existam desde o início da humanidade, o estudo formal das IS é relativamente recente e tende a emergir dos campos de estudos urbanos, desenvolvimento comunitário e empreendedorismo social (Garcia \& Haddock, 2016; Moulaert, 2010; Moulaert, MacCallum, Mehmood \& Hamdouch, 2013; Phillips, Lee, James, Ghobadian \& O’Regan, 2015; Rodriguez, 2009).

Como todo tipo de inovação, as inovações sociais envolvem muito ensaio e erro, e a maioria fracassa ou gera resultados modestos (Hargadon, 2003). Desse modo, não seria de se esperar que um momento de crise ou desastre fosse propício à IS. No entanto, muitas IS surgem em tempos de desastre (Kendra \& Wachtendorf, 2007), quando tanto o estado quanto as forças do mercado estão em xeque (Hayward, Morris, Ramos \& Díaz, 2019) e durante crises (Bessant, Rush \& Trifilova, 2012). Torna-se prática e conceitualmente importante, portanto, saber mais sobre a dinâmica da ocorrência de SI em condições adversas.

Este trabalho relata o surgimento e a evolução de IS depois de um desastre natural na comunidade de Córrego d'Antas, na cidade de Nova Friburgo (RJ). Pelo que sabemos, é o primeiro estudo de campo formal sobre IS na sequência de um desastre natural. Ele foi possível graças à presença casual do primeiro autor naquela comunidade antes, durante e depois do desastre de 2011. Por se tratar de um estudo inusitado, é uma pesquisa indutiva que adota contribuições da grounded theory, sem pretensões positivistas nem hipóteses a priori (Glaser \& Strauss, 1967).

Apesar da natureza indutiva da pesquisa, notamos que nossas observações de campo se alinham com estudos anteriores sobre diferentes aspectos da bricolagem social (Di Domenico, Haugh \& Tracey, 2010) e da intermediação (Obstfeld, Borgatti \& Davis, 2014) - brokerage, em Inglês. São dois constructos que ainda não foram considerados conjuntamente nem em associação à IS. Tal justaposição possibilita expandir e aprofundar o entendimento da IS como fenômeno ligado a um contexto específico. Assim, nossa pergunta de pesquisa a responder foi: quais dinâmicas de IS, bricolagem social e intermediação ocorrem na resposta de uma comunidade a um desastre natural ao longo do tempo?

Nossa contribuição principal relaciona-se com a constatação de que a incidência da bricolagem social e de diferentes tipos de intermediação covaria, é associada a diferentes tipos de IS e obedece a uma lógica temporal ao longo da resposta a um desastre natural. Essa contribuição é parte do fluxo de publicações sobre iniciativas sociais e empreendedorismo contra crises iniciado em nosso trabalho precedente (Nelson \& Lima, 2020).

\section{FUNDAMENTAÇÃO TEÓRICA}

\subsection{Inovação social}

A IS tem sido cada vez mais estudada em diversos contextos, como no desenvolvimento comunitário e nas questões urbanas (Garcia \& Haddock, 2016; Moulaert, 2010). Mesmo que a definição de IS ainda esteja sob debate, a literatura majoritariamente inclui nela a ideia de uma nova contribuição para o aperfeiçoamento social envolvendo uma melhor resposta a uma necessidade social ou meios de aperfeiçoamento das relações sociais (Phills, 2008). Devido à necessidade de pesquisa sobre a IS pós-desastre, preferimos presumir como baixa a necessidade de novidade para ocorrer uma IS. 
A seguinte definição aqui adotada integra pontos centrais das principais definições da literatura: "Qualquer novo objeto ou processo capaz de responder a uma necessidade social e que muda a estrutura socioeconômica e/ou aperfeiçoa a qualidade de vida das pessoas" (Ettorre et al., 2014, p. 139, tradução nossa). Portanto, as IS precisam ser diferentes das práticas locais precedentes, mas não revolucionárias (Moulaert et al., 2013).

Escolhemos essa definição inclusiva devido a nosso foco em um contexto local de um país emergente em que até pequenas iniciativas podem ser usadas no enfrentamento de desafios e gerar importantes melhorias da qualidade de vida. Uma definição inclusiva também parece atrativa devido ao crescente reconhecimento da importância de iniciativas simples criadas por indivíduos no enfrentamento de desafios emergentes - ver o trabalho recente sobre o "empreendedorismo do dia a dia" (Welter, Baker, Audretsch \& Gartner, 2017).

Além da definição inclusiva para a IS, outros aspectos convergentes da literatura sobre IS são relevantes para o entendimento dos dados de nosso campo de pesquisa. Muitos desses aspectos podem ser resumidos sob três temas: satisfação de necessidades, reconfiguração de relações sociais e empoderamento ou mobilização (Mehmood \& Parra, 2013; Moulaert, Martinelli, González \& Swyngedouw, 2005). Cada tema é objeto de explicação e debate, mas a essência de cada um pode ser apresentada com simplicidade. As IS respondem a um conjunto de necessidades humanas que vai além da mera sobrevivência. Buscam-se identidade, comunidade, desenvolvimento pessoal, expressão e crescimento por serem requisitos legítimos para a dignidade humana, mas também por serem meios para a sustentabilidade e a saúde das iniciativas sociais. De modo similar, argumenta-se que as IS de sucesso envolvem mudanças positivas nos padrões de relação, sejam eles interpessoais, intergrupo, institucionais ou entre esses níveis.

Tais mudanças frequentemente envolvem ligações entre "diferentes escalas espaciais" significando que atores de uma localidade passam a se conectar a agências ou entidades orientados a questões regionais, nacionais e/ou globais (Moulaert \& Mehmood, 2011; Van Dyck \& Van den Broeck, 2013). Enfim, esperase que as IS gerem empoderamento e/ou mobilização. O processo de desenvolvimento e execução da inovação ou a natureza da inovação em si frequentemente provocará uma redistribuição de poder, empoderará grupos excluídos e/ou facilitará a ação coletiva. Com frequência, as iniciativas de IS com metas modestas contribuem para a mudança em mais ampla escala envolvendo maior igualdade social (Moulaert \& Mehmood, 2011). Por isso, pode-se observar que as IS tendem a envolver iniciativas de "nível micro" que provocam mudanças de "nível macro". Poder-se-ia esperar que as iniciativas sejam de uma ordem mais elevada para pessoas tentando sobreviver após o desaparecimento súbito de comida, abrigo e água, mas esse pode não ser inteiramente o caso. Pelo contrário, percebemos que os efeitos traumáticos e desorientadores do desastre de Córrego d’Antas (CA a partir daqui) levaram a novas iniciativas socialmente inovadoras. Muitas vezes, estas foram facilitadas pela intermediação feita pelos líderes das iniciativas (líderes locais emergentes e formais) para desenvolver a colaboração interpessoal, intergrupo, entre instituições ou entre diferentes níveis ao conectar variados stakeholders locais e externos à comunidade - conforme discutimos adiante.

Neste artigo, classificamos como IS qualquer elemento que coincida com nossa definição inclusiva. No entanto, estamos bem cientes que as inovações individuais que observamos foram apenas uma parte de um processo transformador mais amplo de IS que envolveu temas inter-relacionados de satisfação de necessidades, reconfiguração de relações e empoderamento. 


\subsection{Uma visão processual dos desastres e da IS}

Conforme mencionamos, a relativa juventude das pesquisas sobre IS, combinada com a falta de estudos empíricos sobre IS pós-desastre, exige uma abordagem indutiva e exploratória. Contudo, há uma longa tradição de pesquisa sobre temas correlatos, que é diversa, mas pertinente, a oferecer reflexões iniciais e direcionamentos promissores.

Percebemos, sobretudo, que tal tradição usa uma abordagem processual, ou ao menos temporal, para crises, desastres e similares. A literatura considera claras fases de resposta a desastres (Contreras, 2016; Haas, Kates \& Bowden, 1977). A literatura sobre resiliência organizacional também identifica uma sequência temporal de fases que acompanha a resposta a choques ambientais de vários tipos (ver, por exemplo, Williams \& Shepherd, 2016). As publicações sobre empreendedorismo igualmente apresentam fortes componentes processuais (Moroz \& Hindle, 2012), assim como as literaturas acerca de institucionalização, mudança institucional e desinstitucionalização (Dacin, Goodstein \& Scott, 2002; Lawrence et al., 2001).

A literatura também costuma observar que diferentes mecanismos relacionais e organizacionais estão associados a diferentes tipos de inovação. Depois de Burns e Stalker (1961), tornou-se axiomática a noção de que inovações são favorecidas por certos tipos organizacionais. Perspectivas dinâmicas mais recentes, como a estruturalista (Giddens, 1984) e as teorias sobre a prática (Bourdieu, 1977), observam interações recursivas entre estrutura, agentes e inovações (Barley \& Tolbert, 1997). Além disso, a literatura em empreendedorismo social identifica interações entre estilos de empreendedorismo e tipos de inovação (Zahra, Gedajlovic, Neubaum \& Shulman, 2009). Ademais, a literatura de sensemaking (Weick, 1993, 1995), que apoia muitas análises de resposta a crises, também adota uma perspectiva temporal. Podemos esperar então que, nas respostas a um desastre, padrões de interação e institucionalização tenham covariância com a geração de IS ao longo do tempo.

\subsection{Bricolagem, intermediação e inovação social: possíveis conexões}

As ideias gerais da seção precedente foram úteis por sustentarem nossas interpretações iniciais sobre as respostas da comunidade ao desastre de 2011. Mas, à medida que nossa pesquisa amadureceu, notamos que muitas de nossas observações de campo e da literatura sobre IS faziam mais sentido quando apoiadas nos conceitos de bricolagem social e intermediação. São dois conceitos ainda apartados do estudo da IS. Por exemplo, após um desastre natural, a IS frequentemente enfrenta a crise oferecendo soluções heroicas. Esse foi o caso depois de vários desastres no Japão, como tufões, terremotos e tsunamis (Lai, 2019). Uma das características da IS respondendo a crises dessa natureza, como se vê nas menções de Lai (2019) ao ativismo voluntário combinado ao papel de variados atores, é ocorrer com a colaboração de diversos stakeholders e também ser promotora de tal colaboração. Assim caracterizada, a IS assemelha-se à noção de IS aberta (Chesbrough \& DiMinin, 2014) e converge com a bricolagem social, que tem a participação de stakeholders como um de seus elementos centrais (Di Domenico et al., 2010).

O relato de Bessant et al. (2012) sobre várias IS emergindo em crises destaca a escassez de recursos e crises como estimulantes da IS. São também estimulantes da bricolagem, ou seja, do "fazer 
algo a partir do nada" (Baker \& Nelson, 2005). Trata-se de um comportamento de superação de limitações comum nas atividades com fins sociais, como descreveram Janssen, Fayolle e Wuilaume (2018), referindo-se ao relevante papel da bricolagem no empreendedorismo social. Estudos da bricolagem identificam várias estratégias para superação da escassez explorando-se recursos à mão (Baker \& Nelson, 2005; Di Domenico et al., 2010; Janssen et al., 2018). Justamente, os seis elementos que compõem a bricolagem social a tornam uma resposta útil e comum em atividades com fins sociais dificultadas por limitações institucionais e de recursos: criação de valor social, rejeição de limitações, virar-se com o que se tem em mãos, improvisação, participação de stakeholders e persuasão (Di Domenico et al., 2010).

A resposta a um desastre é influenciada por stakeholders numerosos e frequentemente desconectados atuando em (e/ou influenciando o) contexto comunitário (Chamlee-Wright \& Storr, 2010; Quarantelli \& Dynes, 1985). Stakeholders são quaisquer grupos ou indivíduos que podem afetar a realização do propósito de uma organização em foco ou são afetados por essa realização (Freeman, 1984). A organização em foco considerada no presente artigo é a associação de moradores de CA, uma pequena organização social de recursos restritos, mesmo fora de uma crise. Tomamos como parte da organização a atuação de líderes emergentes que cumpriram com as funções dos diretores formais dela, conduzindo as respostas comunitárias ao desastre. Nos 17 primeiros dias pós-desastre, a organização desarticulou-se, devido aos efeitos psicológicos e materiais do desastre sobre as vidas de seus diretores, que se ausentaram de suas funções. Os líderes emergentes assumiram também o papel de intermediários. Tal papel voltou aos poucos a ser institucional na associação, ainda que desempenhado predominantemente por esses líderes. Eles foram recebidos, pelos antigos diretores, como diretores de fato da associação durante a crise e, em maio de 2011, eleitos como novos diretores formais. Conectar coordenadamente os stakeholders locais e externos à comunidade (p. ex.: líderes emergentes, diretores formais, moradores, empresários locais, autoridades, políticos municipais e estaduais, poder judiciário, empreiteiras da reconstrução, concessionárias de água e luz e órgãos públicos) e implicá-los é uma função típica de intermediação, desempenhada por organizações comunitárias. Estas buscam bem-estar para sua comunidade, inclusive pela intermediação de relações entre, por um lado, atores locais e, por outro, entre estes e mais stakeholders, sobretudo o Estado (Chaskin, 2003). Tais precisões, apesar de adiantar a análise dos dados, são necessárias para identificar a organização focal e os stakeholders a considerar neste artigo, assim como as partes cujas relações serão vistas como facilitadas pela intermediação na realidade estudada. Ficam também identificados os líderes emergentes como os principais organizadores de iniciativas de bricolagem social e IS.

Habitualmente, as IS não apenas são alvo de colaboração e outras influências de múltiplos stakeholders, mas também são desafiadas por interesses conflitantes, indiferença, resistência e/ou oposição dos stakeholders, em especial dos não colaboradores. Confirma essa concepção a descrição do processo de IS aberta (Chesbrough \& DiMinin, 2014), da qual se pode inferir a importância de se entender a intermediação para a colaboração de stakeholders. O estudo da IS apoiado em intermediação e stakeholders enfrentando urgência, escassez e incapacidade do Estado e da iniciativa privada mostra-se relevante para a teoria e a prática. Tais observações levaram-nos a reexaminar nossos dados de campo sob a luz dos construtos da bricolagem social, sobretudo da participação de stakeholders, assim como da intermediação. Passamos, agora, a uma curta explanação sobre os dois constructos. 


\subsection{Elementos de bricolagem social e o contexto de um desastre}

A bricolagem social refere-se a uma perspectiva emergente que reflete uma ampla tendência iniciada por Simon (1955) para se admitir e explorar as limitações da racionalidade humana. Bricolagem é um conceito proveniente da Antropologia (Lévi-Strauss, 1962) que tem influenciado as perspectivas do institucionalismo e do sensemaking, entre outras. A bricolagem caracteriza-se por um quadro mental fundamentalmente diferente do pensamento moderno, dominado por abstrações desincorporadas usadas pelas pessoas para resolver problemas (Lévi-Strauss, 1962). A bricolagem envolve a recombinação de itens e estímulos concretos provenientes do ambiente imediato sem o uso de abstrações formais.

Um desastre é um evento limitado no espaço e no tempo que impõe perigo severo, estrago físico e ruptura do funcionamento rotineiro da sociedade ou de uma parte desta (Fritz, 1961). Os desastres assemelham-se a acidentes e crises na geração de ruptura, mas variam em causas, origens, previsibilidade e respostas (Shrivastava, Mitroff, Miller \& Miglani, 1988). Dadas a ambiguidade e a pressão típicas dos desastres e também de outros contextos da IS, não é surpresa que nossa pesquisa de campo tenha identificado elementos de bricolagem social em CA. O espaço aqui não permitirá uma explicação detalhada das convergências e divergências de nossa pesquisa de campo com a literatura. No entanto, para nossos propósitos, identificamos contribuições relevantes dos elementos do conceito de bricolagem social (Di Domenico et al., 2010), especialmente da participação de stakeholders, para interpretar os dados de campo. Como já dissemos, tal elemento atribui características de inovação aberta à IS (Chesbrough \& DiMinin, 2014). E ele se combina com os cinco outros elementos para configurar o processo de bricolagem social. Di Domenico et al. (2010) induziram os seis elementos da bricolagem social estudando várias empresas sociais britânicas (que buscavam criar valor social no contexto de recursos escassos, trabalho voluntário frequente e stakeholders diversos), amparando sua pesquisa em Lévi-Strauss (1962) e Baker e Nelson (2005). Os seis componentes que receberam atenção em nossa pesquisa de campo são explicados no Quadro 1. Di Domenico et al. (2010) retomam os dois primeiros elementos de Baker e Nelson (2005). Definem o conceito de "virar-se com o que se tem" como usar recursos à mão para novos propósitos, o que é comum nos trabalhos sobre bricolagem. Contudo, não enfatizam que o conceito envolve soluções viáveis, mas subótimas, como já descrito nas literaturas sobre bricolagem (Baker \& Nelson, 2005), sensemaking (Weick, 1995) e institucionalismo (Rao, Monin \& Durand, 2005). Todavia, acreditamos que essa ideia não seja incoerente com a abordagem de Di Domenico et al. (2010). Sua ideia de "rejeição de limitações" é muito próxima do conceito popularizado por Baker e Nelson (2005), aparentemente com uma ênfase maior na rejeição de limitações relativas a uma ampla variedade de desafios, sejam eles logísticos institucionais ou políticos. A improvisação, ou seja, a fusão da concepção com a execução (Baker, Miner \& Eesley, 2003), não é necessária para virar-se com o que se tem ou rejeitar limitações, mas costuma ser usada quando ambos os processos ocorrem. 


\section{QUADRO 1 DETALHES DA BRICOLAGEM SOCIAL}

\begin{tabular}{|c|c|}
\hline $\begin{array}{l}\text { Componentes da bricolagem } \\
\text { social }\end{array}$ & Explicação \\
\hline $\begin{array}{l}\text { Virar-se com o que se tem } \\
\text { visando-se a um fim social } \\
\text { (com restrita disponibilidade de } \\
\text { recursos) }\end{array}$ & $\begin{array}{l}\text { - Combinação de recursos. } \\
\text { - Criação de algo a partir de nada. } \\
\text { - Uso de recursos descartados, fora de uso ou rejeitados, para novos propósitos. } \\
\text { - Uso de recursos locais ocultos ou mesmo aparentes que outros falham em reconhecer, } \\
\text { valorizar e/ou aproveitar adequadamente. }\end{array}$ \\
\hline $\begin{array}{l}\text { Rejeição de limitações (impostas } \\
\text { por restrições contextuais à } \\
\text { busca de um fim social) }\end{array}$ & $\begin{array}{l}\text { - Tentativas de solução, como respostas táticas, para restrições vindas de estruturas e } \\
\text { regras institucionais penetrantes. } \\
\text { - Subversão das limitações particularmente em sua habilidade de criar valor social. }\end{array}$ \\
\hline Improvisação & $\begin{array}{l}\text { - Junção de concepção e execução em soluções criativas usando-se a abordagem do } \\
\text { "o que melhor serve" dentro dos limites dos recursos escassos disponíveis. } \\
\text { - Tentativa e erro para resolver problemas. }\end{array}$ \\
\hline Criação de valor social & $\begin{array}{l}\text { - Criação de ofertas, bens, serviços e/ou atividades sociais beneficiando-se pessoas } \\
\text { e/ou comunidades. } \\
\text { - Geração de empregos, desenvolvimento de habilidades, treinamento e } \\
\text { desenvolvimento, capital social e coesão comunitária. }\end{array}$ \\
\hline Participação de stakeholders & $\begin{array}{l}\text { - Envolvimento ativo de stakeholders na tomada de decisões, participação como } \\
\text { membro de conselho, determinação e implantação de estratégias, governança e/ou em } \\
\text { processos de consulta/aconselhamento. }\end{array}$ \\
\hline $\begin{array}{l}\text { Persuasão (de outros atores } \\
\text { significativos para alavancar a } \\
\text { aquisição de novos recursos e/ } \\
\text { ou apoio) }\end{array}$ & $\begin{array}{l}\text { - Convencimento de outros para apoiar a realização de objetivos/missões visando à } \\
\text { criação de valor social. } \\
\text { - Obtenção de colaboração dos stakeholders. } \\
\text { - Influência intencional sobre atores-chave em uma direção desejada. }\end{array}$ \\
\hline
\end{tabular}

Fonte: Baseado em Di Domenico et al. (2010).

Os outros três elementos - criação de valor social, participação de stakeholders e persuasão - são distintos do modo como o construto é definido em outros trabalhos e mais próximo da literatura em IS. Nada nas formulações originais de Lévi-Strauss (1962) nem no trabalho subsequente é inerente requerendo que a bricolagem gere valor social. Tampouco, o conceito não tem como inerente a participação de stakeholders ou a persuasão. Assim, tais elementos parecem mais relacionados ao aspecto "social" da bricolagem social que a seu aspecto "bricolagem". De todo modo, as formulações mostram-se amplamente consistentes com os temas centrais da literatura sobre IS identificados anteriormente.

Além da criação de valor social e da realização de serviços para comunidades, iniciativas sociais aumentam o capital social e a coesão comunitária com a participação de stakeholders, até mesmo em estruturas e procedimentos de governança (Di Domenico et al., 2010). Desse modo, tais iniciativas (p. ex.: esforços comunitários contra efeitos do desastre) asseguram enraizamento social e responsabilidade (Pearce, 2003). Asseguram também ampla colaboração para enfrentar desafios, usando, na coletividade servida, a IS gerada por múltiplos agentes (Windrum, Schartinger, Rubalcaba, 
Gallouj \& Toivonen, 2016). Complementarmente, a persuasão (usando argumentação, envolvimento de conhecidos, pressão, diplomacia, advocacia e/ou meios legais, entre outros) influencia a agenda e o pensamento dos stakeholders. Isso produz convergência de interesses, mais legitimidade e mais recursos úteis - favorecendo o engajamento de stakeholders para fazer IS (Di Domenico et al., 2010; Ruebottom, 2013).

\subsection{Intermediação e stakeholders na inter-relação entre escalas espaciais}

Outro construto que se revelou útil, segundo nossos dados, é o de intermediação. Como a bricolagem, a intermediação apresenta-se como um conceito amplo que tem sido usado nas diferentes ciências do comportamento. Ainda assim, as páginas aqui disponíveis permitirão apenas sua breve descrição. Novamente, é um conceito central para descrever a realidade estudada. Também identificamos que ela tem ligação próxima com o tema da participação de stakeholders e da reformulação de relações sociais, fundamental em muito da pesquisa sobre IS. Amparando sua reflexão na robusta tradição de pesquisa sobre redes sociais em Sociologia e Antropologia, pesquisadores da IS estão atentos à configuração do capital social em situações de IS, normalmente focando laços de ligação e de junção, úteis a diferentes propósitos em comunidades e instituições (Coleman, 1988; Granovetter, 1983; Tello-Rozas, 2016).

A intermediação é um subtema destacado na pesquisa sobre redes sociais, mas parece ainda não ter sido explorada na pesquisa sobre IS, talvez devido à suposição de que exista basicamente para gerar benefícios, sobretudo, para o intermediador, que atua entre as partes ligadas. Isso levou à definição restritiva de intermediação como sendo ligar pessoas separadas por um buraco estrutural de uma rede (Burt, 2005). A definição de Burt insiste nas conexões entre dois atores que não ocorreriam, não fosse o contato de ambos com uma terceira parte, o intermediador. Pesquisas mais recentes têm trocado tal concepção por uma mais inclusiva, mais próxima das raízes antropológicas e sociológicas originais do conceito. Obstfeld et al. (2014) argumentam que diversos comportamentos intermediadores importantes podem ocorrer quando o intermediário não é a única conexão entre os atores e quando transações não são o único objetivo da relação. Eles então definem a intermediação como um "comportamento pelo qual um ator influencia, gere ou facilita interações entre outros" (p. 141; tradução nossa). Essa definição mostra-se mais alinhada com os interesses da pesquisa sobre a IS em processos e interações, facilitando fins sociais e incluindo a administração da IS e seus aspectos relativos à participação de stakeholders.

Optamos por essa definição, particularmente, porque ela acomoda mais tipos de intermediação, englobando representação (Lavalle \& Bülow, 2015), advocacia (missão comum das associações de moradores - p. ex.: Chaskin, 2003; Scheller \& Yerena, 2018) e as intermediações catalisadora e de pessoa-meio (Stovel, Golub \& Milgrom, 2011). Todas se mostraram importantes em CA. A representação envolve agir em nome de uma pessoa ou uma entidade quando se lida com outras partes (Lavalle \& Bülow, 2015). A advocacia refere-se à defesa de opiniões e interesses de uma das partes para fazê-los prevalecer junto a outra (ou outras). Por isso, ela envolve uma componente de persuasão, marcando uma sobreposição dos conceitos de intermediação e bricolagem social. A intermediação catalisadora é aquela que põe partes desconectadas em relação ou até mesmo em colaboração; e a intermediação de pessoa-meio consiste na que facilita relações e trocas, em vez de gerar novas relações (Stovel et al., 2011). 


\subsection{A intermediação promovendo a IS}

A intermediação pode ser realizada quando se entretêm ou iniciam relações com diferentes partes e, a partir de suas próprias conexões, promovem-se outras, além de trocas de informação e/ou dinâmicas entre as partes. Iniciativas de bricolagem em rede podem ser mais factíveis usando-se a intermediação, especialmente quando os empreendedores estão procurando por recursos para superar limitações e explorar novas oportunidades (Baker et al., 2003). No entanto, os empreendedores são comumente de um mesmo grupo e de um mesmo setor de atividade - de uma mesma rede. Quando um empreendedor participa de eventos heterogêneos relacionando-se com diferentes pessoas, pode tornar-se uma ligação entre elas (Stam, 2010). Tal posição pode aportar recursos e capacidades, como a colaboração de stakeholders para se explorar oportunidades sociais e criar valor social.

A IS e sua administração podem ser aperfeiçoadas pelos benefícios da participação em diferentes redes. Se os empreendedores podem realizar mais iniciativas de IS aproveitando seus diversos tipos de relação, parece atrativo melhorar seu empreendimento explorando essas relações como fonte de novas ideias, inspirações e oportunidades para a IS. Justamente, a literatura mostra o intermediário como um ator privilegiado em termos de diferentes capitais (social, cultural e informacional, entre outros) por nutrir relações captadoras destes junto a variadas partes e contextos (Burt, 1992; Soda et al., 2018). Há a tendência, portanto, de que tais relações tragam recursos mais poderosos à medida que os empreendedores estão estruturalmente imbricados em uma ampla rede e atuando em diferentes localidades (Smith \& Stevens, 2010). Diferentes tipos de stakeholder em colaboração também podem aumentar o potencial de IS (Chesbrough \& DiMinin, 2014). Ao se combinarem informações, conhecimento e habilidades provenientes de diferentes pessoas e organizações de vários setores, há mais oportunidades para se buscar fins sociais, especialmente aqueles ligados à IS (Phillips et al., 2015). Além disso, devemos reconhecer que a criação da IS feita por múltiplos agentes costuma ser impulsionada por organizações sociais representando o interesse dos cidadãos (Windrum et al., 2016), conforme visto em CA. Pensando-se em stakeholders, todos os atores com alguma influência e/ou interesse são considerados, o que mostra uma grande rede de pessoas e relações influenciando a IS.

Iniciativas típicas da inovação aberta, como a participação de variados stakeholders na IS, parecem ser promissoras particularmente em um contexto de crise no qual articulações criativas e rápidas são necessárias frente à pobreza de recursos e às numerosas necessidades vitais. A combinação de diferentes conhecimentos e habilidades vindos de vários contextos, redes e atores é importante para se entender as necessidades sociais, buscando-se propor soluções de IS. O alcance e a efetividade da IS parecem depender não apenas dos resultados de iniciativas sociais, mas também do resultado da colaboração social (Fromhold-Eisebith, 2004). Assim, a perspectiva da IS aberta ganha destaque, em particular quanto às contribuições potenciais de colaboradores externos ao sistema em que a inovação é gerada (Chesbrough \& DiMinin, 2014). A intermediação mostra-se central, portanto, como viabilizadora ou facilitadora da inovação conectando colaboradores para a inovação. 


\section{MÉTODOS}

O presente tipo de estudo, sob condições extraordinárias, é difícil e raro porque acontecimentos extraordinários são difíceis de se prever e acompanhar. Aproveitamos o fato de o primeiro autor ter estado presente na comunidade durante grande parte das ocorrências estudadas. Ele é originário da região e, quando do desastre, já tinha acumulado dez anos de trabalho no pequeno comércio local de sua família. Embora isso tenha reduzido sua isenção para a pesquisa de campo, ofereceu uma perspectiva não ortodoxa, mas útil. Acreditamos que seu profundo e amplo acesso a dados sobre eventos tão raros mais do que compensam qualquer limitação. Outras eventuais desvantagens metodológicas dessa condição de insider foram compensadas pelo segundo autor, um estrangeiro, com maior distanciamento analítico. A parceria dos autores ajudou a aproveitar melhor suas respectivas condições de insider e outsider (Adler \& Adler, 1987) e a mitigar os desafios contrastantes da marginalidade e da imersão na pesquisa (Dwyer \& Buckle, 2009).

Realizamos 18 entrevistas semiestruturadas com líderes comunitários e moradores durando 90 minutos, em média. Sua transcrição totalizou 290 páginas, incluindo relatos da presidente e do secretário oficiais do momento da tragédia e de cinco membros da comissão de reconstrução, que se elegeram diretores adiante, em maio de 2011. Uma dissertação de mestrado sobre a participação dos moradores na reconstrução (Correa, 2015) reforçou a confirmação dos dados. O Quadro 2 descreve as fontes acessadas.

\section{QUADRO 2 FONTES DE DADOS}

\begin{tabular}{|c|c|c|}
\hline Tipo & Quantidade & Detalhes \\
\hline $\begin{array}{l}\text { Entrevistas } \\
\text { com atores } \\
\text { importantes }\end{array}$ & 18 & $\begin{array}{l}\text { Os informantes foram identificados com processo em bola de neve. Os critérios de } \\
\text { seleção deles foram o alto nível de influência sobre os fenômenos investigados, serem } \\
\text { atores de destaque na comunidade e/ou na história da associação ou serem bem } \\
\text { informados sobre os fenômenos a partir de sua experiência pessoal. Cada informante } \\
\text { recebeu uma curta descrição da pesquisa e de seus objetivos incluindo publicações } \\
\text { e a garantia de minoração de riscos para os informantes. Todos os entrevistados } \\
\text { assinaram uma autorização aceitando participar e a divulgação de seu nome nas } \\
\text { publicações. Os conteúdos foram analisados em detalhe com o software Atlas-ti. }\end{array}$ \\
\hline $\begin{array}{l}\text { Website e } \\
\text { Facebook da } \\
\text { associação - } \\
\text { textos e fotos }\end{array}$ & 1 de cada & $\begin{array}{l}\text { Esses dados públicos foram usados para detalhar, validar, triangular e organizar } \\
\text { cronologicamente os dados coletados de outras fontes, servindo também para ilustrar } \\
\text { fatos quando necessário. Essas fontes foram particularmente úteis na identificação } \\
\text { de desafios enfrentados pela comunidade/associação, assim como de IS e sucessos } \\
\text { divulgados. Os conteúdos foram lidos, sem análise aprofundada, e os elementos mais } \\
\text { relevantes foram usados no desenvolvimento de resultados de pesquisa. }\end{array}$ \\
\hline $\begin{array}{l}\text { E-mails da } \\
\text { comissão de } \\
\text { reconstrução }\end{array}$ & $\begin{array}{c}\text { Muitos, trocados } \\
\text { por cinco anos }\end{array}$ & $\begin{array}{l}0 \text { acesso a todos os e-mails da associação foi concedido aos autores especificamente } \\
\text { para fins de pesquisa, mas o primeiro autor já tinha recebido cópias de muitos deles } \\
\text { no contexto de sua colaboração anterior na comunidade. Essa fonte foi útil para } \\
\text { compreensão de atividades "de bastidores", da preparação de iniciativas, assim } \\
\text { como disputas e desafios enfrentados pela comunidade. Conteúdos filtrados com o } \\
\text { uso de palavras-chave foram lidos atentamente para consideração. }\end{array}$ \\
\hline
\end{tabular}




\begin{tabular}{|c|c|c|}
\hline Tipo & Quantidade & Detalhes \\
\hline Atas de reuniões & $\begin{array}{c}140 \text { antes e } \\
32 \text { após o desastre }\end{array}$ & $\begin{array}{l}\text { Essencialmente, as atas estudadas foram aquelas do pós-desastre. As precedentes } \\
\text { foram superficialmente consideradas para complementar entrevistas para } \\
\text { caracterização sintética das atividades, experiência e condições institucionais da } \\
\text { associação como base para os esforços de recuperação pós-desastre. Mesmo sendo } \\
\text { muito sintéticas, as atas pós-desastre foram analisadas com o Atlas-ti na identificação } \\
\text { de aspectos críticos e de decisões para validar e complementar as entrevistas. }\end{array}$ \\
\hline Estatutos & $\begin{array}{c}3 \text { versões } \\
\text { (aprovadas em } \\
\text { 1984, } 2006 \text { e } \\
2017 \text { ) }\end{array}$ & $\begin{array}{l}\text { Estatutos e atas descrevem as formalidades e as normas burocráticas governando } \\
\text { a associação e suas atividades. Os estatutos indicam como ela pôde ser legalmente } \\
\text { operada, com que estrutura de governança e objetivos oficiais. As três versões } \\
\text { refletem a evolução organizacional viabilizadora de mais iniciativas empreendedoras. } \\
\text { As atas foram analisadas como um registro do contexto institucional das atividades } \\
\text { da associação. }\end{array}$ \\
\hline $\begin{array}{l}\text { Observações } \\
\text { participantes } \\
\text { informais }\end{array}$ & $\begin{array}{l}\text { Várias visitas à } \\
\text { comunidade ao } \\
\text { longo de três anos } \\
\text { para coleta de } \\
\text { dados }\end{array}$ & $\begin{array}{l}\text { As visitas periódicas levaram a (e validaram) novos conceitos e constatações com } \\
\text { dupla confirmação de fatos pelos informantes, abrindo a possibilidade de novas } \\
\text { possibilidades analíticas. }\end{array}$ \\
\hline
\end{tabular}

Fonte: Elaborado pelos autores.

Consistente com a visão processual descrita na fundamentação teórica, a análise de dados foi estruturada em ondas temporais. Cada onda começou com um evento determinante da geração de IS, respectivamente o desastre, a primeira reunião comunitária pós-desastre e a eleição de líderes emergentes. Nossa análise empregou a codificação apoiada pelo software Atlas-ti, uma ferramenta útil para decorticar, classificar e reencontrar segmentos de dados (Friese, 2014). Inicialmente, as entrevistas transcritas e os documentos foram analisados com uma lista preliminar de códigos composta de conceitos sobre bricolagem social (Quadro 1) e caracterização da IS, segundo a definição corrente desse conceito (Ettorre et al., 2014). Adicionando códigos abertos (Strauss \& Corbin, 1998), que emergiram indutivamente, detalhamos conhecimentos sobre aspectos da intermediação citados na fundamentação teórica (representação, advocacia etc.). As seções sobre dados e análises a seguir usam negrito na redação para destacar conteúdos ligados aos códigos.

\subsection{0 caso}

Em 1984, a comunidade de CA fundou uma associação de moradores para defender os interesses da comunidade (objetivo advocatício) e realizar atividades sociais, culturais e recreativas. Uma revisão estatutária de 2006 incluiu atividades representativas que sempre foram realizadas de fato. A associação operou com variados níveis de participação pública e intensidade de suas atividades ao longo dos anos até que o desastre ocorreu em 12 de janeiro de 2011. Pesadas chuvas tropicais causaram graves deslizamentos de terra, lama e matas, além de enchentes, destruindo milhares de propriedades e matando ou ferindo milhares de pessoas na Região Serrana do Estado do Rio de Janeiro. O bairro foi um dos mais atingidos na região (Recuperado de https://corregodantas. wordpress.com/fotos/sobre/). 
Paralisaram-se de imediato os serviços públicos, as vias de locomoção e as mais básicas transações econômicas. As primeiras reações ao desastre em CA foram iniciativas desesperadas, que transitaram gradualmente para comportamentos inovadores, muitos dos quais poderiam ser chamados de IS segundo nossa definição inclusiva. Quase nenhuma dessas atividades era prevista no estatuto da associação. Esta orquestrou, com líderes emergentes, a resposta comunitária à crise após os primeiros dias caóticos. É uma organização de voluntários, sem fins lucrativos. Promove o empoderamento dos cidadãos e a intermediação da comunidade e de seus membros com demais stakeholders, locais e externos. Segundo seu estatuto, todos os moradores ou proprietários de imóveis do bairro são membros, o que totalizava cerca de 4.000 pessoas, mesmo que apenas umas 20 participassem regularmente nas reuniões da associação antes do desastre. Eleições ocorreram trienalmente para 11 cargos, incluindo presidência, vice-presidência e primeira e segunda secretarias. Com poucas exceções, o financiamento era modesto, vindo de raras doações e de festas comunitárias.

Nos meses após o desastre, a estrutura e as rotinas formais da associação reestabeleceram-se gradualmente e propiciaram um fórum oficial para a comunidade enfrentar provações contínuas. As IS continuaram a partir de várias fontes frouxamente coordenadas pela associação. Muitos que se envolveram nas atividades iniciais pós-desastre tornaram-se ativos nas iniciativas da organização, galvanizando uma segunda onda de IS, predominantemente envolvendo modos criativos para provocar órgãos governamentais a cumprirem com suas obrigações legais. A expertise, a motivação e a reputação que emergiram na segunda onda, por sua vez, produziram uma terceira onda de IS com a qual a associação empreendeu iniciativas mais amplas e ambiciosas visando ao bem-estar durável da comunidade. A tal respeito, as dinâmicas da recuperação conectam-se mais claramente com os temas centrais da IS - reconfiguração de relações sociais, empoderamento e mobilização, segundo a literatura. Os dados para as três ondas são analisados nas seções seguintes, cujos conteúdos são resumidos nos Quadros 3, abaixo, e A1 a A4, nos anexos.

\subsection{Primeira onda de IS1}

As reações imediatas ao desastre tenderam a dois extremos. Um foi choque e paralisação. Muitas pessoas bloquearam-se frente à enormidade do desastre. Um número menor realizou improvisações freneticamente, motivadas por necessidades urgentes e perigos. Afetada diretamente por perdas, a liderança formal da associação esteve praticamente inativa nos primeiros dias pós-desastre. Por outro lado, pessoas menos pensativas, convencionais e ordeiras agiram. Sem descanso, jovens ativos, um bombeiro socorrista e moradores sem qualquer posição social formal tenderam mais a agir. Essas pessoas agiram vigorosamente e, segundo certos padrões, descuidadamente, para salvar vidas e propriedades, além de amenizar sofrimentos.

O virar-se com o que se tem e a improvisação ocorreram em quase todas as respostas iniciais ao desastre. Uma enfermaria, refeições emergenciais, uma ponte e macas foram exemplos de virar-se com o que se tem e improvisação, criadas em parte com concepção e execução simultâneas (Quadro A1 - anexos). A rejeição de limitações esteve igualmente presente na primeira onda,

\footnotetext{
${ }^{1}$ Da manhã do desastre até a 1 ${ }^{a}$ reunião comunitária, de 29/01/2011.
} 
envolvendo alguma violação de normas e regulamentos. Por definição, criou-se valor social em todas essas iniciativas. A participação de stakeholders não envolveu stakeholders externos inicialmente (Quadro A5). Concentrou-se em moradores assistindo a outros moradores. Os mais ativos provedores de ajuda emergiram como novos líderes locais, desempenhando também uma função de intermediadores para pôr os demais stakeholders presentes em colaboração. Muitas pessoas estavam desorientadas e, assim, ordens diretas e firmes precisaram ser dadas por esses líderes; e as urgências não possibilitaram diálogo elaborado. Por isso, a intermediação foi moderada e pouco articulada, aplicada a rapidamente pôr em colaboração os atores locais. As ações emergenciais foram feitas por pequenos grupos sem intermediação, apoio ou autorização de qualquer autoridade ou terceira parte externa à comunidade. Com três dias, já havia intensa presença de socorristas, técnicos, autoridades e outros stakeholders externos. Vinham de áreas não afetadas da cidade e, principalmente, da capital do estado, com equipes que até mesmo tinham policiais militares atuando temporariamente como bombeiros socorristas e servidores públicos comuns improvisados no serviço subótimo de coleta e identificação de corpos. Isso dificultou que famílias encontrassem e enterrassem seus mortos, ainda que coletados. Virar-se com o que se tem foi norma para stakeholders locais e externos participantes.

\subsection{Segunda onda de IS}

Um segundo período de IS na recuperação (Quadro A2) começou em 17 dias. Os perigos imediatos se dissiparam, feridos tinham sido removidos e tratados. Moradores sumidos tinham sido localizados, enterrados ou dados por mortos. Alimentos e suprimentos já chegavam novamente, ainda que precariamente. Contudo, os serviços básicos não tinham sido reestabelecidos; e a frustração com a paralisia do governo era visível. Os líderes da associação tinham combinado uma reunião com alguns dos mais ativos atores locais dos socorros improvisados e das iniciativas mais dependentes do virar-se com o que se tem para decidirem sobre mais ações. De algum modo, os moradores entenderam que se tratava de uma reunião aberta, e cerca de 150 pessoas irritadas compareceram. O imprevisto, aparentemente negativo e intratável, foi convertido em benefício da mobilização comunitária, com significativo ajuste do tipo de reunião por bricolagem institucional e improvisação. Muito da reunião acabou referindo-se a reclamações emocionadas contra a negligência e a má conduta governamentais. Gradualmente, os ânimos acalmaram-se. "Fizemos uma lista bem completa de reivindicações. Queríamos uma pequena comissão de reconstrução, e ela acabou tendo 30 membros!" (Sandro - bombeiro e presidente da associação após maio de 2011).

A comissão tornou-se uma importante IS de governança. Diretores da associação e demais interessados passaram a se encontrar semanalmente e a atuar regularmente pela comissão atacando problemas. Como fórum central de participação e envolvimento de stakeholders locais e externos (Quadro A5), a comissão lançou líderes formais e informais da associação em atividades frequentes de representação e advocacia, como Sandro explica: "O trabalho era intenso e fomos muito expostos

\footnotetext{
${ }^{2}$ Da primeira reunião comunitária, feita em 29/01 até 30/04/2011.
} 
pela mídia. Diretores de serviços públicos, pessoas do terceiro setor e outras participavam das reuniões [participação dos stakeholders]. Isso movimentou muito e gerou bons resultados".

Em paralelo às atividades atrativas e não ameaçadoras desse fórum de stakeholders, ocorriam ações mais agressivas. A associação virou-se com o pouco que tinha criando um website que divulgou danos e esforços de recuperação. Nele, foram postados textos e fotos de denúncia de descaso, falta de atuação e má conduta de stakeholders externos, como pessoas, construtoras e autoridades que deveriam fazer avançar a reconstrução. Por iniciativa própria, moradores também fizeram dois protestos contra a negligência governamental, fechando a rodovia Friburgo-Teresópolis. Houve outros elementos de bricolagem social na segunda onda. Os protestos não autorizados rejeitaram limitações. Iniciativas, como mutirões comunitários fazendo o que era dever do Estado, claramente foram além dos limites tradicionais de comportamento e também constituíram uma provocação contra os governantes. Os protestos tiveram certo grau de improvisação, porém mais moderado do que nos frenéticos salvamentos iniciais. Houve também menos virar-se com o que se tem na segunda onda, mesmo que certas atividades empregassem instrumentos e métodos que eram subótimos frente a padrões normais.

A participação de stakeholders mais variados (muitos sendo externos, dessa vez) foi central para todas as iniciativas da segunda onda. Enquanto as iniciativas emergenciais da primeira onda contaram com a participação espontânea de partes afetadas e benfeitores, o voluntariado foi menor e mais diverso na segunda fase. Assim, a participação de stakeholders tornou-se mais ampla, seletiva e problemática. Houve um claro declínio de atenção e de envolvimento de stakeholders à medida que passou o senso de urgência. A persuasão tornou-se mais central conforme a necessidade de ação não era mais tão óbvia e urgente e havia mais tempo para debate e deliberação. O engajamento de stakeholders externos (como servidores públicos e autoridades) também tornou a persuasão mais central. Como na primeira onda, a criação de valor social estava clara em todas as iniciativas.

A partir da narrativa feita, podemos ver que os elementos de bricolagem social declinaram na nova fase, mas não está claro o que tomou seu lugar. O engajamento de stakeholders diminuiu, ainda que permanecesse uma participação mais superficial de uma variedade deles. Um espectro mais amplo de stakeholders surgiu. Responsáveis por serviços públicos e privados começaram a frequentar as reuniões da comissão. A imprensa tornou-se muito mais presente. Provocadas pelo website, várias partes interessadas envolveram-se ao menos tomando conhecimento de fatos e enviando mensagens, indo além da solidariedade com donativos de pessoas menos informadas. Líderes também foram a repartições públicas levar reivindicações comunitárias e advogados, ativistas e voluntários externos engajaram-se. 
RAP | Inovação e bricolagem sociais com intermediação após um desastre em Córrego d’Antas

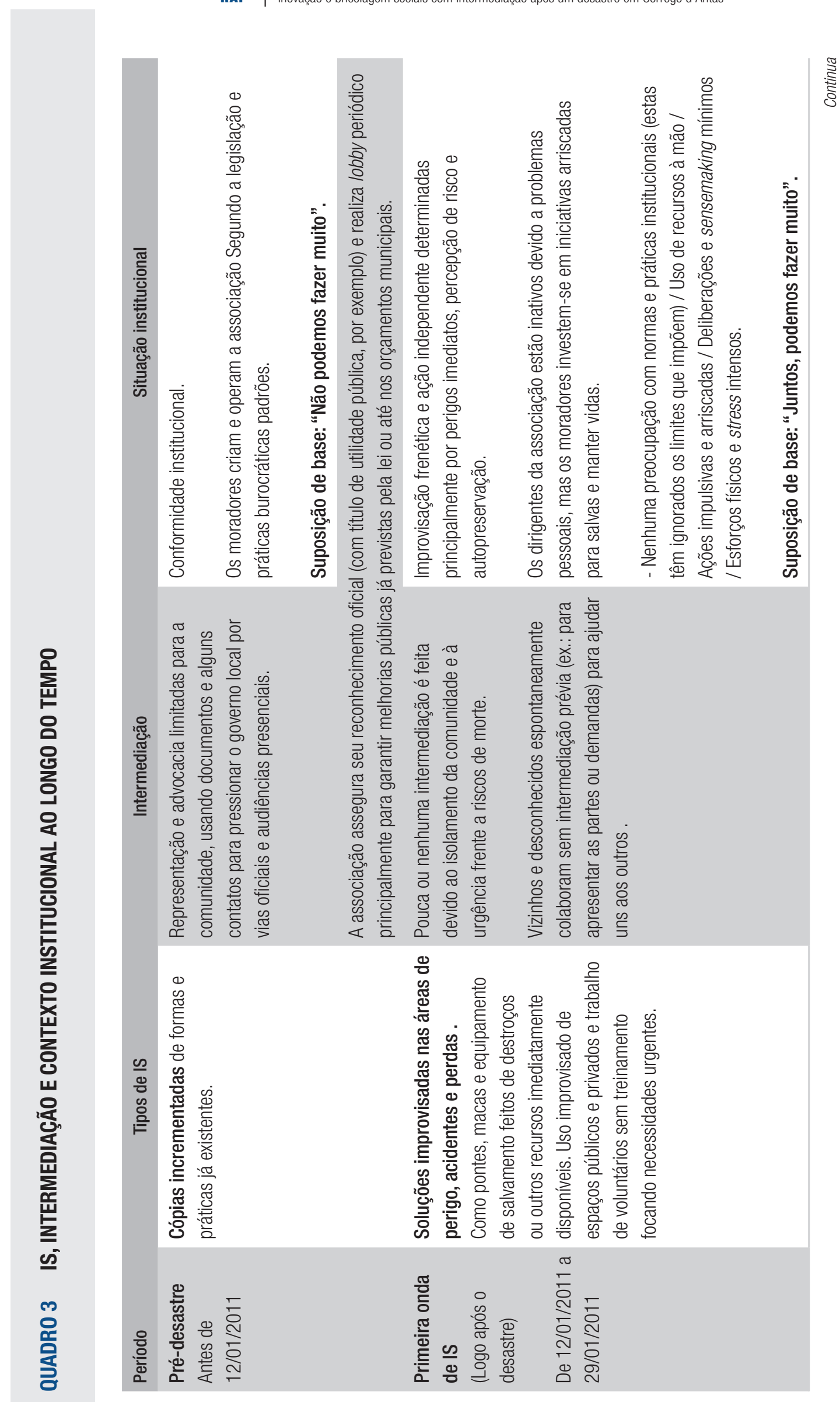

ReVista de AdMinistração PÚBlica ｜ Rio de Janeiro 55(3): 594-624, maio - jun. 2021 
RAP | Inovação e bricolagem sociais com intermediação após um desastre em Córrego d’Antas

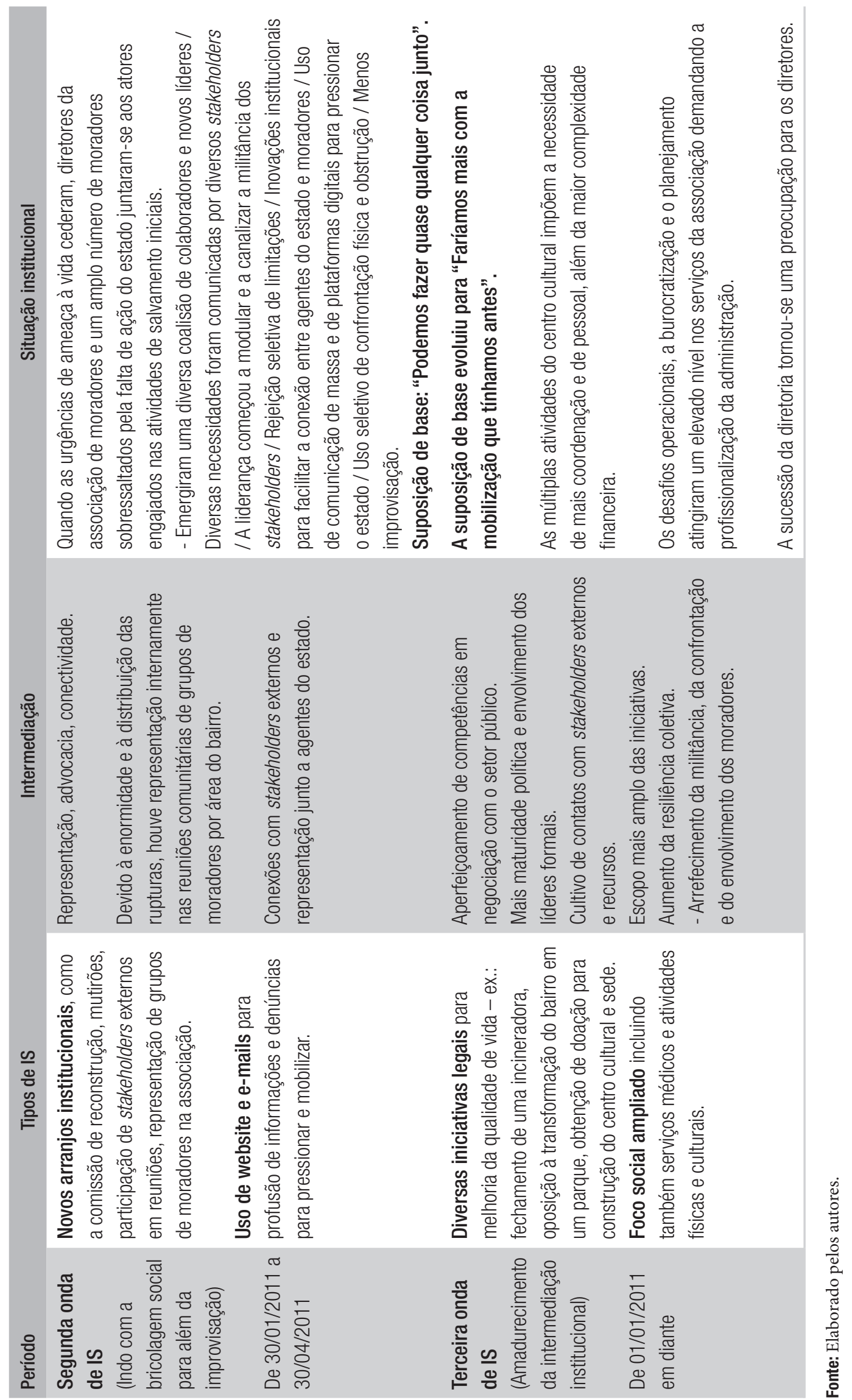

ReVISTA de AdMinistração Pública ｜ Rio de Janeiro 55(3): 594-624, maio - jun. 2021 
A persuasão também requer exame na segunda onda de IS. Nessa fase, ela se tornou mais presente, porém de modo mais diversificado e nuançado. As denúncias no website tiveram intenção persuasiva, mas de um jeito diferente das interações com funcionários públicos. $\mathrm{O}$ fechamento da rodovia, mesmo sem a participação dos líderes da associação, envolveu ainda outro tipo de persuasão, como os mutirões e as iniciativas de reconstrução de pontes, que constrangeram autoridades na mídia, forçando-as a agir.

Tais nuances mostram a bricolagem social como insuficiente para a compreensão completa das ações da associação e das IS da comunidade respondendo ao desastre. Em busca de mais explicação, encontramos os estudos da intermediação, que lida mais completamente com os modos com que são construídas, mantidas e desenvolvidas as conexões entre diferentes atores - aqui, os stakeholders. Revisando a segunda onda de IS, identificamos variados modos de intermediação (Quadro A4). Os três seguintes parecem ter o maior poder explicativo.

\subsubsection{Representação}

Nessa modalidade, um ou mais atores representam os cidadãos em seus interesses junto a outros stakeholders (funcionários, autoridades, empresários etc.), o que envolveu duas dimensões. $\mathrm{Na}$ primeira, os líderes tiveram que acalmar os ânimos dos moradores, usando a persuasão e as interações colegiadas desses stakeholders locais para estabelecer consensos e prioridades ou, até mesmo, canalizar a agressividade e o desconforto coletivos para ações específicas. A segunda dimensão foi a modulação e a apresentação dos interesses comunitários a stakeholders externos. Esse papel de representação foi complexo e envolveu paradoxos, pois colocava em interação variados stakeholders com culturas e objetivos distintos e conflitantes, a começar pelos próprios moradores.

\subsubsection{Advocacia}

É mais simples que a representação, ainda que tenha envolvido diferentes intensidades e estratégias para persuadir stakeholders a agir de modo alinhado com os interesses da comunidade. Denúncias divulgadas e a mobilização com mutirões foram atividades fortes de advocacia. Outro tipo, que observamos mais amplamente na terceira onda, envolveu ações formais legais, aparentemente mais amenas. Os tipos variaram em termos de persuasão, participação de stakeholders e rejeição de limitações.

\subsubsection{Intermediação catalisadora}

Esse foi talvez o mais simples e um dos mais produtivos tipos de intermediação. Envolveu meramente apresentar partes com interesses comuns ou necessidades complementares. Muitos stakeholders acabaram forjando novas colaborações comparecendo às reuniões da comissão de reconstrução. Mesmo visitas ao website conectaram partes, de certo modo, também por persuadi-las a agir. Por exemplo, o website, além das mídias jornalísticas, deu informações a stakeholders, inclusive locais, que os estimularam a se voluntariar. 


\subsection{Terceira onda de IS ${ }^{3}$}

No início da terceira onda (Quadro A3), os confrontos e negociações com o Estado (usando-se advocacia e persuasão) para o reestabelecimento imediato de serviços tinham diminuído. Líderes informais surgidos nos primeiros momentos pós-desastre foram eleitos para cargos formais em $1^{\circ}$ de maio de 2011. A reputação da associação como uma força com a qual contar estava estabelecida. A associação tinha também buscado assistência especializada (p. ex.: advogados e consultores voluntários) para desenvolver estruturas e procedimentos formais.

Essa onda foi marcada por iniciativas de maior escala, formalidade e complexidade, aspectos que mitigaram a bricolagem social. Três eventos destacaram-se. Para revolta da comunidade, o Estado determinou que o bairro inteiro fosse demolido e transformado em um parque fluvial. Assistentes legais voluntários ajudaram a assegurar a suspensão da determinação. Segundo, uma importante doação financeira da cidade suíça de Fribourg foi recebida para a construção de instalações comunitárias. Após várias considerações, decidiu-se pela construção de um centro cultural com sede da associação, continuando a pressão comunitária por uma creche municipal. Terceiro, a associação avançou com o Ministério Público no fechamento de uma incineradora local de rejeitos tóxicos. $\mathbf{O}$ esforço começou meses antes do desastre, mas o fechamento ocorreu em 2015, resultado de atividades das mais duradouras e persistentes de advocacia, representação e persuasão da associação. $\mathrm{O}$ tratamento de resíduos comumente envolve graves ilegalidades no Brasil, tornando temerária a oposição advocatícia, configurada como persistente rejeição de limitações.

$\mathrm{Na}$ terceira onda, muitos moradores receberam, do Estado, uma ordem intimidadora de desapropriação de seu imóvel com uma oferta de indenização, considerada insuficiente e que frequentemente não chegava. Novamente, a associação intermediou assistência legal para negociação, litígio e/ou divulgação de queixas dos moradores.

A terceira onda mostra uma maciça transição da bricolagem para a intermediação e o isomorfismo institucional. O envolvimento dos stakeholders locais caiu (Quadro A5). A improvisação praticamente desapareceu. A rejeição de limitações continuou na oposição contra desapropriações parcamente indenizadas, indenizações não recebidas e o projeto do parque, mas isso se fez predominantemente pelos canais institucionais-legais. De modo similar, enquanto a advocacia e a persuasão ainda atuavam na construção de consenso e de aceitação de medidas formais, as vias legais foram então mais importantes. O virar-se com o que se tem e o uso de habilidades informais com soluções subótimas não eram mais proeminentes. Dos elementos de bricolagem social, a criação de valor social foi o que se manteve mais ativo. Ainda assim, essa fase mais institucionalizada foi bem produtiva em IS frequentemente mais ambiciosas que aquelas das ondas anteriores, como aquelas relativas à criação do centro cultural e de um posto médico local.

${ }^{3}$ A partir da eleição dos líderes emergentes, ocorrida em 01/05/2011. 


\section{DISCUSSÃO E CONCLUSÕES}

O desastre em CA claramente estimulou várias IS ao longo das três ondas temporais consideradas. Há também ampla evidência de que essas inovações se desdobraram em outras. Os primeiros esforços pós-desastre uniram as pessoas de maneiras que propiciaram engajamento, sofisticação de iniciativas e foco em uma sequência temporal clara. Igualmente importante foi que o padrão e as características das iniciativas populares tomadas e apoiadas por diversos atores espacialmente dispersos coincidem com os principais atributos da IS identificados na literatura.

Além do animador resultado de que a IS pode emergir de um desastre mortal, o que mais aprendemos? Vemos três contribuições potenciais. Talvez a mais significativa seja que uma forma institucional muito específica (quiçá anti-institucional) descreveu muito dos processos de ajustamento e de inovação em CA. A ideia de que a bricolagem - uma proeminente alternativa à racionalidade administrativa clássica - esteve presente nas IS pós-desastre é importante como um possível quadro teórico descritivo e normativo para pesquisadores da IS. Revisamos quatro estudos de caso recentes sobre IS em países latinos (La Trinitat Nova, na Espanha; Montemor-o-Novo e Aldoar, em Portugal; e Lima, no Peru) e não encontramos qualquer referência a bricolagem, effectuation ou outras visões alternativas à racionalidade administrativa, apesar de a maior parte das histórias dos casos incluir algum elemento da bricolagem social, como persuasão, improvisação e participação de stakeholders (André, Henriques \& Malheiros, 2009; Tello-Rozas, 2016; Rodriguez, 2009).

Também notamos que a intermediação acompanhou e reforçou a bricolagem social em CA. Algo também importante é que os comportamentos de intermediação mais comuns em CA foram as alternativas não tradicionais e desviantes da intermediação estrutural clássica descrita por Burt (2005), segundo a qual atores individuais (tertius gaudens) intermediam partes anteriormente desconectadas para obter ganhos. Também é significativo que a intermediação tradicional relativa a buraco estrutural raramente apareceu e foi mais comum nas últimas ondas. A literatura sobre IS costuma se apoiar no papel de ligação e união do capital social (Coleman, 1988), que corresponde frouxamente à dicotomia clássica de laços fortes e fracos (Granovetter, 1983). O caso de CA sugere que a categoria "ligação" pode ser expandida para incluir os quatro tipos de intermediação que apresentamos na fundamentação teórica, cada um com suas próprias implicações para a geração de inovação e reformulação de relações sociais. A descoberta dessas dimensões de intermediação no processo de IS pode ser útil para a análise de futuros casos de IS e a análise retrospectiva de estudos passados.

Contrariamente às fases de organização, estruturação e empoderamento de Tello-Rozas (2016), identificamos as fases pré-desastre e três ondas temporais de IS em CA. A fase pré-desastre, que durou muitos anos, apresentou elementos de organização, estruturação e limitado empoderamento, mas a primeira onda de IS foi bem diferente, e aparentemente única, devido à urgência, à emoção, ao esforço concentrado e à natureza espontânea desse curto período. Parece seguro dizer que a maioria das respostas a desastres contém um notável período em que estruturas e papéis de rotina fracassam e a improvisação e a bricolagem social dominam. A fase de intermediação com maturação institucional claramente contém elementos de estruturação e empoderamento com alguma organização. Contudo, acreditamos que muito do dinamismo e do engajamento das pessoas nessa fase foi forjado nas situações cruciais da fase de urgências.

Acreditamos que, nessa primeira fase, reside a origem de algumas das consequências positivas inesperadas de desastres. Em termos de IS, eles reconfiguram as relações sociais ao 
desfazerem redes de relação e criarem novas, juntando pessoas, até mesmo desconhecidas, para enfrentar malefícios, além de gerar empoderamento com a comunidade e agir autonomamente contra urgências. Essa natureza processual e dinâmica das reações ao desastre também parece compreender grandes desafios para as IS provocadas por ele, mesmo apresentando oportunidades para aproveitamento de sinergias e de efeitos multiplicadores provenientes da solidariedade, do envolvimento e do empoderamento ocorridos na fase de urgências. Um desafio é a redução do envolvimento popular. Outro consiste na necessidade de se canalizar proveitosamente a colaboração comunitária e os elos com pessoas de outras localidades. Grandes resultados de processos dinâmicos podem se aplicar às IS e às comunidades em recuperação pós-desastre. Ocorrências ambientais graves podem abrir oportunidades para o progresso social porque tendem a "descongelar" (Rao, 2008) o sistema social. Tal descongelamento pode ser muito bem aproveitado por meios alternativos, como a bricolagem social e a intermediação catalizadora, mais do que com a lógica tradicional burocrática.

A ruptura causada pelo desastre leva-nos a uma terceira contribuição. Durante o pré-desastre, a associação era regida por regras institucionais e promoveu modestas IS, frequentemente similares a estruturas e iniciativas de fora. $\mathrm{O}$ desastre suspendeu regras institucionais e impediu complexas ponderações, impondo malpensadas ações para pessoas cuidarem de si e de outros. A intermediação praticamente desapareceu. De início, alguns líderes emergentes chegaram a juntar moradores (stakeholders locais), inclusive desconhecidos entre si, e pô-los em colaboração em ações humanitárias. Contudo, grande parte das ações foi realizada diretamente por pessoas próximas com pouco tempo ou inclinação para procurar terceiras partes ou intermediação.

A segunda onda, marcada por improvisação e bricolagem social em geral, com o virar-se com o que se tem, foi rica em tipos de IS e complexidade de soluções e intermediações. Pela primeira vez, responsáveis por serviços públicos e moradores encontraram-se frequentemente no bairro. Todos eram bem-vindos em reuniões e assembleias. $\mathrm{O}$ website da associação e a notoriedade do desastre, combinados a iniciativas enérgicas de reivindicação, captou ampla atenção midiática e atraiu especialistas externos. Líderes locais que estiveram inativos durante a crise inicial retornaram à ativa $\mathrm{e}$ apoiaram os líderes emergentes. Esse conjunto de forças fez avançar todos os tipos de intermediação, da advocacia à simples colocação de terceiros em contato. A amplitude e a frequência das IS foram impressionantes, de moradores bloqueando tratores que poderiam estragar casas ao fechamento ilegal da rodovia, fotorregistro de violações contratuais e ações mais sutis, ficando as iniciativas mais elaboradas a cargo dos líderes emergentes com a associação. Participação de stakeholders, persuasão, improvisação, teste de limites institucionais e intermediação são aspectos que ajudaram CA a superar seus desafios, contando com uma ampla coalizão de atores semiautônomos envolvidos em muitas iniciativas de líderes emergentes confiáveis, que ganharam credibilidade com ações pró-sociais corajosas nos momentos mais críticos.

A terceira onda de IS, marcada pela maturação da intermediação institucional, apresentou grandes inovações, como a criação do centro cultural e o fechamento da incineradora tóxica, que quase certamente não ocorreriam sem mais maturidade e credibilidade, ampliadas nas ondas precedentes. No entanto, também houve enfraquecimento de algumas forças comunitárias. Diminuíram os modos criativos de pressão sobre instituições, o envolvimento dos moradores na tomada de decisão e na mobilização coletivas e o sacrifício de interesses individuais em favor dos coletivos. Aumentou-se a dependência de organizações externas. 
Aspectos mais amplos acerca da IS também se mostraram. À medida que a liderança comunitária se envolveu com stakeholders externos, o envolvimento local e a autonomia diminuíram. As frustrações dos moradores frequentemente ameaçaram desarticular relações externas. Isso evoca o questionamento se grandes paradoxos e tensões organizacionais identificados na literatura atualmente em voga (Putnam, Fairhurst \& Banghart, 2016) são menos relevantes em um contexto anômalo de um grande desastre e, se afirmativo, por quê. Por outro lado, será que os paradoxos locais de CA revelam tensões de pós-desastres em geral ou apenas daqueles em contexto comunitário? Parece que a tensão autonomia-dependência e a tensão entre achar internamente suas próprias soluções, por vezes controversas, e as pressões externas por conformidade são tensões importantes em muitos contextos e podem merecer atenção sistemática em pesquisas futuras. São provocativas as aparentes diferenças de "densidade" dos paradoxos ao longo do tempo: pouco senso de paradoxo antes do desastre, um bruto paradoxo no pós-desastre imediato (p. ex.: inação sob choque versus salvamento de outros), múltiplos paradoxos e múltiplas IS durante a fase de bricolagem social e menos equilíbrio entre paradoxos na fase de maturidade institucional. Quanto essa observação esclarece ou é esclarecida por perspectivas processuais como as teorias de ciclo de vida organizacional ou empreendedor ou teorias temporais de inovação?

Acreditamos que essa questão abre variadas linhas para futuras pesquisas que, oxalá, começarão a revelar explicações da importante sequência de eventos descritos em nossos dados. A suspensão do sensemaking e de instituições no pós-desastre imediato poderia tornar fácil separar as 48 a 72 horas do pós-desastre como um vazio cognitivo e social, irrelevante para os esforços comunitários subsequentes. Contudo, pensamos que essa fase inicial foi determinante para as ações subsequentes de vários modos. Destaca-se o fato de que aqueles que foram mais ativos nos primeiros momentos de alto risco acabaram por dirigir a associação de moradores formal, assim como as atividades menos formais de bricolagem social, aparentemente fundamentais para engajar o Estado e mobilizar a comunidade. É também possível que a brutalidade da destruição e das perdas de vida tenha estimulado os moradores a deixar de lado convenções e alguma reserva e, assim, confrontar energicamente o estado e prestadores de serviço na mídia, na internet, em protestos, em mutirões e em interlocução direta. Tal postura quase certamente criou um polo de um paradoxo extensivamente enfrentado na segunda onda de IS. Os líderes emergentes tiveram que canalizar, modular e aproveitar a raiva comunitária de maneiras que captaram a atenção pública e a reação do estado sem inviabilizar seu papel de intermediação representando a comunidade em seus pleitos frente às autoridades. Parece também aceitável pensar que as ações heroicas daqueles que agiram nas urgências pós-desastre deram credibilidade a esses atores como intermediadores, devido a seu grande altruísmo.

Começamos este artigo notando o paradoxo de que, curiosamente, crises e desastres costumam gerar IS apesar da escassez, do estresse e das rupturas que produzem. Nosso estudo da resposta ao desastre de janeiro de 2011 em CA sugere que a interação entre a bricolagem social e a intermediação pode ajudar a explicar o paradoxo e talvez, até mesmo, prover um modelo para ações futuras e para políticas públicas. Antes do desastre, havia menos elementos de bricolagem social na estrutura e nas ações da associação de moradores estudada. A associação tinha se engajado em atividades de representação e advocacia, que são variações da intermediação, com as quais stakeholders locais, como moradores carentes de serviço público, eram postos em interação construtiva com stakeholders externos, como o governo local e prestadores de serviço público. Ocorria criação de valor social, mas pouca IS. Logo após o desastre, improvisações caóticas fizeram emergir elementos de bricolagem social 
que, em parte, fizeram emergir várias IS. Concomitantemente, essa fase testemunhou uma grande expansão do escopo e da diversidade do envolvimento de stakeholders e das várias intermediações. Partindo da primeira hora, sem intermediação e apenas com o envolvimento de moradores, o tempo e as condições evoluíram de modo que líderes emergentes e a associação gradativamente operassem todos os tipos de intermediação (representação, advocacia, catalisadora e pessoa-meio) com quase toda a categoria possível de stakeholders, incluindo a imprensa, o terceiro setor, o governo, o judiciário, outras comunidades e atores nacionais e internacionais (ver também o Quadro A5, nos anexos). Após esse período de efervescência, a comunidade assentou-se em um padrão mais deliberado e institucionalizado de geração de IS e valor social, mas, ainda assim, continuou a ser o berço de importantes IS de escala crescente. As IS observadas mudaram e aprimoraram as relações com (e entre) stakeholders, a começar pelos próprios moradores e depois com externos. Também como previa nossa definição de IS, elas melhoraram a qualidade de vida na comunidade, inclusive por irem além da recuperação pós-desastre, associadas a relevantes iniciativas ambientais e socioculturais que continuaram a aprimorar os padrões de interação e de criação de valor social.

As relações que observamos entre conceitos não provam qualquer causalidade, e nossa contribuição emergiu indutivamente a partir de um estudo de caso único. No entanto, descobrimos que, enfatizando a concomitância dos variados aspectos de bricolagem social e de intermediação com a IS, a ocorrência e a trajetória das respostas da comunidade aos efeitos do desastre, feitas por intermédio dos líderes emergentes e da associação, se tornaram mais inteligíveis. Rejeitar limitações, improvisar e envolver stakeholders e as demais ações relevantes que observamos, sendo empreendidas com o uso de diversos tipos de intermediação para implicar uma população progressivamente mais ampla e diversa de stakeholders, parecem-nos ser um modo promissor para aumentar a ocorrência e a maturidade das IS.

As claras sobreposições entre o empreendedorismo social, a bricolagem social e a IS indicam que muito trabalho resta a ser feito para integrar contribuições dos diferentes campos e subdisciplinas ligados a esses temas. Ainda assim, esperamos que nosso estudo dos acontecimentos em uma comunidade tenha ajudado a demonstrar as similaridades e a utilidade subjacentes dessas perspectivas para se compreender como comunidades podem superar os efeitos dos cada vez mais numerosos desastres naturais que a ganância e a inépcia humanas agravam. Esperamos, também, que nossa pesquisa ajude a pôr sob a luz o que é universal e o que é idiossincrático nos processos abordados. A exata resposta de uma comunidade a um desastre mostra-se única e estabelece-se com um misto de personalidades, ações e fatores contextuais. Apesar desse caráter único, nosso relato dos esforços heroicos de uma modesta comunidade contribuirá de algum modo para ampliar o diálogo sobre como diversas pessoas e instituições podem enfrentar adversidades de modo criativo e humano. 


\section{REFERÊNCIAS}

Adler, P. A., \& Adler, P. (1987). Membership roles in field research. Thousand Oaks, CA: Sage.

André, I., Henriques, E. B., \& Malheiros, J. (2009). Inclusive places, arts and socially creative milieu. In D. MacCallum, F. Moulaert, J. Hillier, \& S. V. Haddack (Eds.), Social innovation and territorial development (pp. 149-166). Farnham, UK: Ashgate.

Baker, T., Miner, A. S., \& Eesley, D. T. (2003). Improvising firms: bricolage, account giving and improvisational competencies in the founding process. Research Policy, 32(2), 255-276.

Baker, T., \& Nelson, R. E. (2005). Creating something from nothing: resource construction through entrepreneurial bricolage. Administrative Science Quarterly, 50(3), 329-366.

Barley, S. R., \& Tolbert, P. S. (1997). Institutionalization and structuration: studying the links between action and institution. Organization Studies, 18(1), 93-117.

Bessant, J., Rush, H., \& Trifilova, A. (2012). 'Jumping the tracks': crisis-driven social innovation and the development of novel trajectories. Die Unternehmung, 66(3), 221-242.

Bourdieu, P. (1977). Outline of a theory of practice. Cambridge, UK: Cambridge University Press.

Burns, T., \& Stalker, G. M. (1961). The management of innovation. London, UK: Tavistock Publications.

Burt, R. S. (1992). Structural holes. Cambridge, MA: Harvard University Press.

Burt, R. S. (2005). Brokerage and closure: an introduction to social capital. Oxford, UK: Oxford University Press.

Chamlee-Wright, E., \& Storr, V.H. (2010). The role of social entrepreneurship in post-Katrina community recovery. International Journal of Innovation and Regional Development, 2(1/2), 149-164.

Chaskin, R. J. (2003). Fostering neighborhood democracy: legitimacy and accountability within loosely coupled systems. Nonprofit and Voluntary Sector Quarterly, 32(2), 161-189.

Chesbrough, H., \& DiMinin, A. (2014). Open social innovation. In H. Chesbrough, W. Vanhaverbeke \& J. West (Eds.), New frontiers in open innovation (pp. 169-188). Oxford, UK: Oxford University Press.
Coleman, J. (1988). Social capital in the creation of human capital. The American Journal of Sociology, 94, S95-S120.

Contreras, D. (2016). Fuzzy boundaries between postdisaster phases: the case of L'Aquila, Italy. International Journal of Disaster Risk Science, 7(3), 277-292.

Correa, M. S. T. (2015). A política no desastre em Nova Friburgo/RJ: uma análise da participação de moradores na reconstrução do bairro Córrego d'Antas (Dissertação de Mestrado). Universidade Federal Fluminense, Niterói, RJ.

Dacin, M. T., Goodstein, J., \& Scott, W. R. (2002). Institutional theory and institutional change: Introduction to the special research forum. Academy of Management Journal, 45(1), 45-56.

Di Domenico, M., Haugh, H., \& Tracey, P. (2010). Social bricolage: theorizing social value creation in social enterprises. Entrepreneurship: Theory and Practice, 34(4), 681-703.

Dwyer, S. C., \& Buckle, J. L. (2009). The space between: on being an insider-outsider in qualitative research. International Journal of Qualitative Methods, 8(1), 54-63.

Ettorre, D., Bellantuono, N., Scozzi, B., \& Pontrandolfo, P. (2014). Towards a new definition of social innovation. In J. Y. Zhao, P. O. Pablos, \& R. Tenysson (Eds.), Organizational innovation and IT governance in emerging economies. Pennsylvania, EUA: IGI Global Publisher.

Freeman, R. E. (1984). Strategic management: a stakeholder approach. Boston, MA: Pitman.

Friese, S. (2014). Qualitative data analysis with ATLAS.ti. Thousand Oaks, CA: Sage Publications.

Fritz, C. E. (1961). Disaster. In R. K. Merton, \& R. A. Nisbet (Eds.), Contemporary social problems (pp. 651-694). New York, NY: Harcourt, Brace and World.

Fromhold-Eisebith, M. (2004). Innovative milieu and social capital - complementary or redundant concepts of collaboration-based regional development? European Planning Studies, 12(6), 747-765.

Garcia, M. \& Haddock, S. V. (2016). Special issue: housing and community needs and social innovation responses in times of crisis. Journal of Housing and the Built Environment, 31(3), 393-407. 
Giddens, A. (1984). The constitution of society. Cambridge, UK: Polity Press.

Glaser, B. G., \& Strauss, A. L. (1967). Discovery of grounded theory: strategies for qualitative research. Chicago, IL: Aldine.

Granovetter, M. (1983). The strength of weak ties: a network theory revisited. Sociological Theory, 1, 201-233.

Haas, J. E., Kates, R. W., \& Bowden, M. J. (Eds.) (1977). Reconstruction following disaster. Cambridge, MA: MIT Press.

Hargadon, A. (2003). How breakthroughs happen: the surprising truth about how companies innovate. Brighton, MA: Harvard Business Press.

Hayward, R. A., Morris, Z., Ramos, Y. O., \& Díaz, A. S. (2019). “Todo ha sido a pulmón”: community organizing after disaster in Puerto Rico. Journal of Community Practice, 27(3-4), 249-259.

Janssen, F., Fayolle, A., \& Wuilaume, A. (2018). Researching bricolage in social entrepreneurship. Entrepreneurship \& Regional Development, 30(3-4), 450-470.

Kendra, J. M., \& Wachtendorf, T. (2007). Community innovation and disasters. In H. Rodríguez, W. Donner, \& J. E. Trainor (Eds.), Handbook of disaster research (pp. 316-334). New York, NY: Springer.

Lai, O. K. (2019). Apocalyptic learning for sustainability in aged Japan - positive reciprocities and social innovations in the information age. In Chong A, \& Chi I. Social work and sustainability in Asia: facing the challenges of global environmental changes. London, UK: Routledge.

Lavalle, A. G., \& Bülow, M. (2015). Institutionalized brokers and collective actors: different types, similar challenges. Social Movement Dynamics: New Perspectives on Theory and Research from Latin America, 157. Recuperado de http://repositorio. conicyt.cl/handle/10533/219643

Lawrence, T. B., Winn, M. I., \& Jennings, P. D. (2001). The temporal dynamics of institutionalization. Academy of Management Review, 26(4), 624-644.

Lévi-Strauss, C. (1962). The savage mind. Chicago, IL: The University of Chicago Press.
Mehmood, A., \& Parra, C. (2013). Social innovation in an unsustainable world. In F. Moulaert, D. MacCallum, A. Mehmood, \& A. Hamdouch (Eds.), The international handbook on social innovation: collective action, social learning and transdisciplinary research (pp. 53-66). Cheltenham, UK: Edward Elgar.

Moroz, P. W., \& Hindle, K. (2012). Entrepreneurship as a process: toward harmonizing multiple perspectives. Entrepreneurship Theory and Practice, 36(4), 781-818.

Moulaert, F. (2010). Social innovation and community development - concepts, theories and challenges. In F. Moulaert, F. Martinelli, E. Swygedouw, \& S. Gonzáles (Eds.), Can neighborhoods save the city? (pp. 4-16). London, UK: Routledge.

Moulaert, F., MacCallum, D., Mehmood, A., \& Hamdouch, A. (2013). The international handbook on social innovation: collective action, social learning and transdisciplinary research. Cheltenham, UK: Edward Elgar.

Moulaert, F., Martinelli, F., González, S., \& Swyngedouw, E. (2005). Towards alternative model(s) of local innovation. Urban Studies, 42(11), 1969-1990.

Moulaert, F., \& Mehmood, A. (2011). Spaces of social innovation. In A. Pike, A. Rodriguez-Pose, \& J. Tomaney (Ed.), Handbook of local and regional development (pp. 212-225). London, UK: Routledge.

Nelson, R., \& Lima, E. (2020). Effectuations, social bricolage and causation in the response to a natural disaster. Small Business Economics, 54(3), 721-750.

Obstfeld, D., Borgatti, S. P., \& Davis, J. (2014). Brokerage as a process: decoupling third party action from social network structure. In Brass, D., Labianca, G., \& Mehra A. Contemporary perspectives on organizational social networks. Bradford, UK: Emerald Group Publishing.

Pearce, J. (2003). Social enterprise in anytown. London, UK: Calouste Gulbenkian Foundation.

Phills, J. (2008). Rediscovering social innovation. Stanford Social Innovation Review, 6(4), 36-43.

Phillips, W., Lee, H., James, P., Ghobadian, A., \& O'Regan, N. (2015). Social innovation and social entrepreneurship: a systematic review. Group \& Organization Management, 40(3), 428-461. 
Putnam, L. L., Fairhurst, G. T., \& Banghart, S. (2016). Contradictions, dialectics, and paradoxes in organizations: a constitutive approach. The Academy of Management Annals, 10(1), 65-171.

Quarantelli, E. L., \& Dynes, R. R. (1985). Community response to disasters. In Sowder, B. (Ed.). Disasters and mental health selected contemporary perspectives (pp. 158-168). Washington, DC: U.S. Government Printing Office.

Rao, H. (2008). Market rebels: how activists make or break radical innovations. Princeton, NJ: Princeton University Press.

Rao, H., Monin, P., \& Durand, R. (2005). Border crossing: bricolage and the erosion of categorical boundaries in French gastronomy. American Sociological Review, 70(6), 968-991.

Rodriguez, A. (2009). Social innovation for neighbourhood revitalization: a case of empowered participation and integrative dynamics in Spain. In D. MacCallum, F. Moulaert, J. Hillier, \& S. V. Haddack (Eds.), Social innovation and territorial development (pp. 81-100). Farnham, UK: Ashgate.

Ruebottom, T. (2013). The microstructures of rhetorical strategy in social entrepreneurship: Building legitimacy through heroes and villains. Journal of Business Venturing, 28(1), 98-116.

Scheller, D. S., \& Yerena, A. (2018). Neighborhood concerns and mobilization patterns of homeowners and neighborhood associations. Journal of Public Management \& Social Policy, 24(2), 82-121.

Shrivastava, P., Mitroff, I., Miller, D., \& Miglani, A. (1988). Understanding industrial crises. Journal of Management Studies, 25, 285-303.

Simon, H. A. (1955). A behavioral model of rational choice. The Quarterly Journal of Economics, 69(1), 99-118.

Smith, B. R., \& Stevens, C. E. (2010). Different types of social entrepreneurship: the role of geography and embeddedness on the measurement and scaling of social value. Entrepreneurship and Regional Development, 22(6), 575-598.

Soda, G., Tortoriello, M., \& Iorio, A. (2018). Harvesting value from brokerage: individual strategic orientation, structural holes, and performance. Academy of Management Journal, 61(3), 896-918.

Stam, W. (2010). Industry event participation and network brokerage among entrepreneurial ventures. Journal of Management Studies, 47(4), 625-653.

Stovel, K., Golub, B., \& Milgrom, E. M. M. (2011). Stabilizing brokerage. Proceedings of the National Academy of Sciences, 108(4), 21326-21332.

Strauss, A., \& Corbin, J. (1998). Basics of qualitative research: techniques and procedures for developing grounded theory. Thousand Oaks, CA: Sage.

Tello-Rozas, S. (2016). Inclusive innovations through social and solidarity economy initiatives: A process analysis of a Peruvian case study. VOLUNTAS: International Journal of Voluntary and Nonprofit Organizations, 27(1), 61-85.

Van Dyck, B., \& Van den Broeck, P. (2013). Social innovation: a territorial process. In Moulaert, F., MacCallum, D., Mehmood, A., \& Hamdouch, A. (Eds.). The international handbook on social innovation: collective action, social learning and transdisciplinary research (pp. 131-141). Cheltenham, UK: Edward Elgar.

Weick, K. E. (1993). The collapse of sensemaking in organizations: the Mann Gulch disaster. Administrative Science Quarterly, 38, 628-52.

Weick, K. E. (1995). Sensemaking in organizations. Thousand Oaks, CA: Sage.

Welter, F., Baker, T., Audretsch, D. B., \& Gartner, W. B. (2017). Everyday entrepreneurship - a call for entrepreneurship research to embrace entrepreneurial diversity. Entrepreneurship: Theory and Practice, 41(3), 311-321.

Windrum, P., Schartinger, D., Rubalcaba, L., Gallouj, F., \& Toivonen, M. (2016). The co-creation of multiagent social innovations: A bridge between service and social innovation research. European Journal of Innovation Management, 19(2), 150-166,

Zahra, S. A., Gedajlovic, E., Neubaum, D. O., \& Shulman, J. M. (2009). A typology of social entrepreneurs: motives, search processes and ethical challenges. Journal of Business Venturing, 24(5), 519-532. 


\section{Edmilson Lima}

https://orcid.org/0000-0002-1833-8742

Ph.D. em Administração; Pós-doutorado em Administração pela HEC Montreal, Canadá; Professor e pesquisador do Programa de Pós-Graduação em Administração (PPGA - mestrado e doutorado) na Universidade Nove de Julho (UNINOVE); Cofundador e diretor científico da Associação Nacional de Estudos em Empreendedorismo e Gestão de Pequenas Empresas (ANEGEPE); Editor científico da revista PODIUM Sport, Leisure and Tourism Review; Vice-presidente para o Brasil na Association Internationale de Recherche en Entrepreneuriat et PME. E-mail: edmilsonolima@gmail.com

\section{Reed Nelson}

https://orcid.org/0000-0001-7460-0488

Ph.D. em Comportamento Organizacional pela Cornell University, EUA; Endowed Chair in Innovation \& Entrepreneurship na Faculdade de Administração da Universidade da Louisiana.

E-mail: nelson.reed@louisiana.edu 


\section{ANEXOS}

QUADRO A1 PRIMEIRA ONDA DE IS (DE 12 A 29 DE JANEIRO DE 2011)

\begin{tabular}{|c|c|c|}
\hline IS observadas & Citações ilustrativas & $\begin{array}{l}\text { Componentes de } \\
\text { bricolagem social }\end{array}$ \\
\hline $\begin{array}{l}\text { Equipes de socorro } \\
\text { aplicando bricolagem social }\end{array}$ & $\begin{array}{l}\text { Encontramos tábuas para imobilizar feridos e as apoiamos nos } \\
\text { ombros, carregando as vítimas primeiro para a enfermaria da casa } \\
\text { do Mário. Levamos as que estavam em estado grave em maca } \\
\text { improvisada para o hospital, passando a pé por muita lama e } \\
\text { perigos em vários quilômetros. (Rafael de Morais, gerente de uma } \\
\text { loja de autopeças.) } \\
\text { Não tínhamos equipamento. Cortamos uma corda em vários } \\
\text { pedaços, que viraram a amarração necessária e uma guia longa } \\
\text { para estabilizar e guiar um barco emprestado por um morador. (...) } \\
\text { Também usamos outro pedaço longo de corda segurado por dois } \\
\text { rapazes fortes, um em cada margem, que ficava rente à lâmina } \\
\text { d'água. Se alguém caísse no rio, poderia se agarrar a ela e se } \\
\text { salvar. Era tudo improvisado! (Sandro.) }\end{array}$ & $\begin{array}{l}\text { Bricolagem } \\
\text { (como definida por Baker } \\
\text { e Nelson, 2005) } \\
\text { Virando-se com o que se } \\
\text { tem por uma finalidade } \\
\text { social } \\
\text { Rejeição de limitações }\end{array}$ \\
\hline $\begin{array}{l}\text { Ponte improvisada feita } \\
\text { com destroços }\end{array}$ & $\begin{array}{l}\text { Eu trabalho com obras e assim vi que podíamos fazer uma ponte } \\
\text { usando destroços de madeira e fios de eletricidade caídos dos } \\
\text { postes. Achamos que isso seria um jeito de enfrentar o sofrimento } \\
\text { das pessoas que estavam isoladas (Edmo Teixeira, pedreiro.) }\end{array}$ & $\begin{array}{l}\text { Criação de valor social } \\
\text { Útil para outras ondas }\end{array}$ \\
\hline $\begin{array}{l}\text { Efeito bola de neve das IS } \\
\text { IS comunitárias inspiraram } \\
\text { talentos complementares a } \\
\text { se implicarem e ajudarem }\end{array}$ & $\begin{array}{l}0 \text { desastre afetou outras localidades também. Então por que toda } \\
\text { essa organização ocorreu apenas aqui em nossa comunidade? } \\
\text { Porque nós mesmos tomamos a iniciativa e isso foi contagiante. } \\
\text { Tínhamos algumas pessoas com um senso de liderança - Edmo é } \\
\text { um exemplo. Depois, mais pessoas, com treinamento apropriado, } \\
\text { se juntaram a nós. (Sandro.) }\end{array}$ & $\begin{array}{l}\text { lideranças, revelação de } \\
\text { talentos e status para } \\
\text { intermediação }\end{array}$ \\
\hline
\end{tabular}

Fonte: Elaborado pelos autores. 


\section{QUADRO A2 SEGUNDA ONDA DE IS (DE 29 DE JANEIRO A 30 DE ABRIL DE 2011)}

IS observadas
Uma nova dimensão de
governança a partir da
reunião comunitária de 29
de janeiro

\section{Modos de recrutamento de pessoas de certa projeção como colaboradores}

Comissão de reconstrução (CR) e reuniões: uma esfera de práticas e discussões de baixo risco útil para se integrar talentos, novos líderes e auxílio

\section{CR e reuniões como} esferas de implicação de stakeholders

Modo que dispensa a intermediação e cria coalisões para fazer avançar melhor o que interessava à comunidade

\section{Mutirões de moradores para limpeza e reconstrução}

Os resultados positivos galvanizaram a comunidade e colaboradores externos para mais iniciativas

Com cobertura da imprensa, eles envergonharam as autoridades e as forçaram a agir

\section{Implicação de voluntários} e auxílio externos na realização de iniciativas locais, majoritariamente definidas pelos próprios moradores
Citações ilustrativas

Componentes de bricolagem social

Lembro que a gente organizou tudo ali na hora daquela reunião, que eu mediei. Alguém fez a ata. A gente arrumou um papel em branco [flipchart] e você [0 primeiro autor] fez umas anotações. A gente fez uma lista de demandas, que tinha desde problema com água até casa em risco, passando por todas as necessidades básicas, sociais. Foi uma lista bem extensa. Quisemos fazer uma comissão pequena pra buscar com rapidez a solução dos problemas listados. Ela acabou começando com 30 pessoas. (Sandro.)

0 trabalho da comissão foi dos mais importantes, pois a diretoria formal não estava podendo exercer seu papel. (Cláudio Werneck, então secretário da associação, depois de ter sido presidente por duas vezes e vice-presidente por uma.)

Foi graças a essa comissão liderada por Sandro que pudemos avançar naquele momento, comissão que depois [da eleição de maio] passou a se chamar 'Grupo Gestor', quando o Sandro se tornou presidente da associação. (Cláudio.)

Houve uma manifestação dos moradores que parou a rodovia passando no bairro, com barricadas. Veio a polícia, mobilizou-se a mídia, mobilizou-se o Poder Público. Foi um grande evento da comunidade. E eu fiquei muito curioso: 'Quem é que puxou esse movimento? Não foi a associação. Descobri que foi o Edmo e mais um rapaz. Chamei os dois para entrarem para a comissão. Veio só o Edmo. (Sandro.)

0 Marquinho é um fenômeno para trabalhar. Ele é um cara de ação, entrou para a comissão e tornou-se diretor de mutirão. Ele tem um papel importante porque é funcionário da Prefeitura e trabalha na equipe de manutenção do bairro, como zelador do bairro na limpeza. (Sandro.)

A gente fazia reunião da comissão toda semana e assembleias quinzenais. Era intenso 0 trabalho e a nossa imagem estava muito presente na mídia. (Sandro.)

Vinham gestores públicos, pessoas do terceiro setor (ONGs) e tudo mais [políticos, gestora da companhia municipal de água...] para participar de nossas reuniões, inclusive da comissão. Isso foi um ganho, gerou todo um movimento. Os convidados traziam mais pessoas e nos colocavam em contato também com outras pessoas. No conjunto, eles nos ajudaram com pedidos de informação e outras questões em diferentes órgãos. (Sandro.)

Fizemos mutirões. Vi, com isso, que realmente valia a pena a gente se empenhar, assumir uma posição na diretoria pra conseguir melhorias pra comunidade. (Edmo.)

Tinha o Silvinho, empresário local de terraplenagem, que cedia o tratorista e 0 trator. Mas acabaram vindo também caminhões e trabalhadores da prefeitura, nesse regime de mutirão. (Sandro.)

Em 2014, começamos um movimento pra construção da ponte para carros em mutirão. Arrecadamos recursos, aquela coisa... Num final de semana, eu estava num bar tomando cerveja. Para minha surpresa, o político encarregado de gerir toda a crise estava me procurando, pois não conseguia me telefonar. É uma arma que aprendemos que é mito eficaz: tentar fazer o que é dever do estado e, assim, o estado se sente ameaçado. Pouco depois ele apareceu dizendo que o estado faria a ponte. (Edmo.)

0 trabalho comunitário sério inicial, pautado por valores humanos e comprometimento com a coletividade, atraiu mais gente querendo ajudar. Vieram até pessoas de outros municípios. Foi complicado porque isso gerou mais trabalho. Tivemos que acolher as pessoas, depois encaixá-las nas atividades do bairro, na associação e ajudá-las a fazer seu projeto. (Sandro.)
Bricolagem social crescente

Participação de stakeholders

Persuasão

Criação de valor social

Rejeição de limitações

Menos improvisação

Virando-se com o que se tem por uma finalidade social

\section{Elemento} de destaque relacionado: intermediação

Fonte: Elaborado pelos autores. 


\section{QUADRO A3 TERCEIRA ONDA DE IS (DE 1 DE MAIO DE 2011 A 2016)}

\begin{tabular}{|c|c|c|}
\hline IS observadas & Citações ilustrativas & $\begin{array}{l}\text { Componentes de } \\
\text { bricolagem social }\end{array}$ \\
\hline $\begin{array}{l}\text { Alianças e colaboração } \\
\text { com outras ONGs e } \\
\text { especialistas }\end{array}$ & $\begin{array}{l}\text { Eu disse "pô, a gente tem que fazer algum evento para envolver as famílias; a } \\
\text { gente está cansado e só sai para fazer mutirão? Então vamos fazer algo pra } \\
\text { descontrair." Eu fui e levei isso lá para essa ONG. Aí eles gostaram e foram } \\
\text { atrás de recursos para nos ajudar e fizemos a festa comunitária com a ajuda } \\
\text { deles. (Sandro.) } \\
\text { Consegui dois consultores, um era o próprio Tião Guerra e o outro era o... (me } \\
\text { fugiu o nome) - o cara é super, presta consultoria para grandes empresas } \\
\text { de São Paulo, multinacionais; o cara e fera. Aí os dois iam ajudar, um mais } \\
\text { humanista e, o outro, mais técnico. (Sandro.) }\end{array}$ & \\
\hline $\begin{array}{l}\text { Escoramento no alto de } \\
\text { uma grande pedra de suas } \\
\text { partes sob risco de cair } \\
\text { Ele começou em } 2014 \\
\text { como efeito de pressões da } \\
\text { associação sobre o estado }\end{array}$ & $\begin{array}{l}\text { As obras sendo feitas no alto de uma das grandes pedras de nosso bairro } \\
\text { foram uma conquista da comunidade com o trabalho da associação de } \\
\text { moradores. (Sandro - em um e-mail para o Grupo Gestor em 18/03/2014.) }\end{array}$ & $\begin{array}{l}\text { Participação de } \\
\text { stakeholders } \\
\text { Persuasão }\end{array}$ \\
\hline \multirow{3}{*}{$\begin{array}{l}\text { Construção da sede com } \\
\text { um centro cultural } \\
\text { usando uma doação suíça; } \\
\text { local de posterior oferta } \\
\text { de consultas médicas em } \\
\text { aliança com órgãos públicos }\end{array}$} & $\begin{array}{l}\text { Um importante passo foi construir o centro cultural. Tínhamos decido fazer } \\
\text { uma creche (porque a gente precisava realmente de uma). Só que, em } \\
\text { reunião, concluímos que quem tinha que construir a creche era a prefeitura, } \\
\text { senão ela poderia se apropriar da creche e do terreno por ser ela obrigada por } \\
\text { lei a oferecer esse serviço. (Edmo.) }\end{array}$ & \multirow{3}{*}{$\begin{array}{l}\text { Criação de valor } \\
\text { social } \\
\text { Rejeição de } \\
\text { limitações } \\
\text { Menos } \\
\text { improvisação }\end{array}$} \\
\hline & $\begin{array}{l}\text { A intenção com o centro cultural é também termos cursos, principalmente a } \\
\text { oferecer para crianças e adolescentes, que não podem mais ficar em creche, } \\
\text { tirar essas crianças da rua e dar a elas a oportunidade de fazer cursos pra } \\
\text { preencherem o tempo com coisas sadias. (Sandro.) }\end{array}$ & \\
\hline & Veja também: https://www.facebook.com/CasaDeSebastiao. & \\
\hline $\begin{array}{l}\text { Parcerias para assistência } \\
\text { gratuita em gestão de risco } \\
\text { de desastre, consultoria para } \\
\text { a associação etc. }\end{array}$ & $\begin{array}{l}\text { Pensamos em uma consultoria que nos facilitasse definir metas, missão, } \\
\text { caminhos, modelos de gestão, ações estratégicas etc., para, posteriormente, } \\
\text { promovermos uma revisão estatutária, para a qual já temos o auxilio voluntário } \\
\text { de um administrador e de advogados. (Sandro - num e-mail para a comissão } \\
\text { de reconstrução em 17/07/2015.) }\end{array}$ & \multirow[t]{3}{*}{$\begin{array}{l}\text { relacionado: } \\
\text { aperfeiçoamento } \\
\text { da intermediação }\end{array}$} \\
\hline $\begin{array}{l}\text { Oferta de atividades } \\
\text { culturais e de lazer no } \\
\text { centro cultural (dança, } \\
\text { artesanato ...) }\end{array}$ & $\begin{array}{l}\text { Estamos em vias de inaugurar nossa sede que será um centro cultural, onde } \\
\text { deverão acontecer diversas ações voltadas ao benefício dos moradores locais } \\
\text { e, possivelmente, da região. Já pretendemos tocar alguns projetos no centro } \\
\text { a partir da inauguração, pois já temos voluntários para isso. (Sandro - num } \\
\text { e-mail para a comissão de reconstrução em 17/07/2015.) }\end{array}$ & \\
\hline $\begin{array}{l}\text { Oferta de serviços médicos } \\
\text { com um médico cubano } \\
\text { disponibilizado pelo Programa } \\
\text { Mais Médico }\end{array}$ & $\begin{array}{l}\text { Já temos consultas médicas gratuitas (apenas para moradores de nosso } \\
\text { bairro)! As consultas serão às quartas e quintas. (Facebook da associação } \\
\text { - 06/03/2016 - https://www.facebook.com/associacaomoradorescorrego } \\
\text { dantas). }\end{array}$ & \\
\hline
\end{tabular}

Fonte: Elaborado pelos autores. 


\section{QUADRO A4 EVOLUÇÃO DA INTERMEDIAÇÃO NO TEMPO}

\begin{tabular}{|c|c|c|}
\hline $\begin{array}{l}\text { Períodos de IS contra as } \\
\text { necessidades de serviços }\end{array}$ & Atividades de intermediação & Que características tinha a intermediação? \\
\hline $\begin{array}{l}\text { Pré-desastre } \\
\text { IS raras e tênues }\end{array}$ & $\begin{array}{l}\text { Antes do desastre ocorrido em 11- } \\
12 \text { de janeiro } \\
\text { Tentativa de obter melhores serviços } \\
\text { públicos. }\end{array}$ & $\begin{array}{l}\text { - Modalidades de intermediação simultânea e sequencial: } \\
\text { * representação\#. } \\
\text { * advocacia\#\#. } \\
\text { - Persuasão pelo diálogo, com tato e boas relações para } \\
\text { obter a colaboração dos moradores, além dos órgãos } \\
\text { públicos, prestadores de serviço, homens de negócio e } \\
\text { demais stakeholders. } \\
\text { - A associação já desenvolveu uma boa reputação entre os } \\
\text { stakeholders como um ator não extremista e conciliador. }\end{array}$ \\
\hline $\begin{array}{l}\text { Primeira onda } \\
\text { Impactos do desastre - dias e } \\
\text { semanas críticos } \\
0 \text { desastre ampliou } \\
\text { muitíssimo a necessidade } \\
\text { de serviço na comunidade } \\
\text { IS intensas salvando vidas } \\
\text { e melhorando as condições } \\
\text { básicas de vida }\end{array}$ & $\begin{array}{l}\text { De } 11 \text { a } 29 \text { de janeiro } \\
\text { Vazio de intermediação causado pela } \\
\text { desarticulação. }\end{array}$ & $\begin{array}{l}\text { - Paralisia do papel de intermediação da associação. } \\
\text { - As conexões da comunidade foram cortadas já que ela } \\
\text { estava focada em sua autorrecuperação. } \\
\text { - Os intermediários precedentes estavam inativos sob o } \\
\text { impacto do desastre. } \\
\text { - Emergência de novos líderes locais organizando a IS. } \\
\text { - As IS deram-Ihes status e legitimidade para se tornarem } \\
\text { diretores da associação e novos intermediários. }\end{array}$ \\
\hline $\begin{array}{l}\text { Segunda onda } \\
\text { IS e intermediação visando à } \\
\text { reconstrução } \\
\text { IS melhorando as condições } \\
\text { de vida }\end{array}$ & $\begin{array}{l}\text { De } 29 \text { de janeiro a abril de } 2013 \\
\text { Novo ímpeto focando a representação e } \\
\text { a advocacia. }\end{array}$ & $\begin{array}{l}\text { - Modalidades de intermediação simultânea ou sequencial: } \\
\text { * representação\# - mais intensa que no pré-desastre. } \\
\text { * advocacia\#\# - mais intensa que no pré-desastre. } \\
\text { * intermediação catalizadora. }\end{array}$ \\
\hline $\begin{array}{l}\text { Terceira onda } \\
\text { IS focando interesses mais } \\
\text { gerais, como a saúde na } \\
\text { comunidade, lazer e cultura, } \\
\text { fazendo o que é obrigação } \\
\text { dos órgãos públicos } \\
\text { IS melhorando as condições } \\
\text { de vida }\end{array}$ & $\begin{array}{l}\text { De abril de } 2013 \text { a } 2016 \\
\text { Foco nas intermediações de tipo } \\
\text { pessoa-meio e diplomático. }\end{array}$ & $\begin{array}{l}\text { * intermediação do tipo pessoa-meio. } \\
\text { - A associação tem uma reputação positiva como } \\
\text { interlocutor de qualidade, usando a intermediação } \\
\text { diplomática e uma abordagem simpática com agentes } \\
\text { públicos. }\end{array}$ \\
\hline
\end{tabular}

\# Representação: por exemplo, na apresentação de problemas comunitários aos órgãos públicos com reivindicação de soluções.

\# Advocacia: por exemplo, na defesa de interesses da comunidade e em ações legais contra uma incineradora irregular e poluidora.

Fonte: Elaborado pelos autores. 


\section{QUADRO A5 TAKEHOLDERS NAS DIFERENTES ONDAS TEMPORAIS}

\begin{tabular}{|c|c|}
\hline Períod & Variedade de stakeholders e sua atuação local \\
\hline $\begin{array}{l}\text { Pré-desastre } \\
\text { IS raras e tênues }\end{array}$ & $\begin{array}{l}\text { * Locais, com pouca mobilização (moradores: pessoas comuns, pequenos empresários locais, líderes } \\
\text { comunitários, especialistas....). } \\
\text { * Externos esporadicamente presentes na comunidade (políticos buscando votos, autoridades e servidores } \\
\text { públicos convidados). } \\
\text { * Externos pressionados pela associação para oferecer serviços à comunidade (concessionária de ônibus, } \\
\text { serviços de luz, água e pavimentação, políticos e autoridades). }\end{array}$ \\
\hline $\begin{array}{l}\text { Primeira onda (17 } \\
\text { dias) } \\
\text { Impactos do } \\
\text { desastre - dias e } \\
\text { semanas críticos }\end{array}$ & $\begin{array}{l}\text { * Dois primeiros dias: apenas os locais (moradores: pessoas comuns, pequenos empresários locais, líderes } \\
\text { emergentes, especialistas...) atuaram em auxilio de urgência, de modo autônomo (com a comunidade ilhada } \\
\text { pelo desastre), em certos casos com relações facilitadas pela intermediação dos líderes emergentes. } \\
\text { * A partir do terceiro dia: há também atuação crescente de agentes de segurança e bombeiros como } \\
\text { socorristas e na coleta de corpos - recebem orientações dos atores locais mais colaborativos. } \\
\text { * A partir do sexto dia, aproximadamente: atuação mais contextualizada dos externos, agora mais } \\
\text { frequentemente orientados e intermediados pelos líderes emergentes, já reconhecidos e procurados como tal. } \\
\text { * A partir do décimo dia, aproximadamente: além dos demais stakeholders, atuam operadores de } \\
\text { equipamentos pesados, engenheiros e encarregados com grandes construtoras, frequentemente em má- } \\
\text { conduta combatida por moradores. }\end{array}$ \\
\hline $\begin{array}{l}\text { Segunda onda } \\
\text { IS e intermediação } \\
\text { visando a } \\
\text { reconstrução }\end{array}$ & $\begin{array}{l}\text { * Ampliação rápida da variedade e da quantidade de stakeholders colaboradores. } \\
\text { * Os líderes emergentes são elevados a porta-vozes da comunidade e aclamados como coordenadores } \\
\text { das reuniões comunitárias, integrando-se como diretores informais à associação. } \\
\text { * Os locais se reuniram, se planejaram e têm pauta de demandas prioritárias a guiar a ação dos líderes e } \\
\text { da associação, assim como a intermediação e a relação com stakeholders. } \\
\text { * Criou-se a comissão de reconstrução, como base de encaixe da participação e da colaboração dos } \\
\text { stakeholders locais e externos. } \\
\text { * } 0 \text { mosaico de stakeholders atuando no bairro se amplia com todos mencionados acima, mais voluntários } \\
\text { externos, ONGs externas, assistentes jurídicos, grupos de religiosos voluntários, representantes de órgãos } \\
\text { públicos - inclusive da justiça, para pressionar legalmente por soluções. } \\
\text { * A gestão da colaboração dos numerosos stakeholders (particularmente de voluntários que chegam } \\
\text { à comunidade e dela partem) fica virtualmente impossível e a massa flutuante de colaboradores atua } \\
\text { localmente de modo semiautônomo. } \\
\text { * stakeholders locais com grande e animada participação em reuniões comunitárias, cada qual motivado } \\
\text { principalmente por seus próprios problemas e interesses, buscando apoio coletivo para causas pessoais } \\
\text { - o que é propício a conflito e desarticulação. }\end{array}$ \\
\hline $\begin{array}{l}\text { Terceira onda } \\
\text { IS focando } \\
\text { interesses mais } \\
\text { gerais, como } \\
\text { a saúde na } \\
\text { comunidade, lazer } \\
\text { e cultura }\end{array}$ & $\begin{array}{l}\text { * Ampliação rápida da variedade e da quantidade de stakeholders colaboradores. } \\
\text { * Diminuiu sensivelmente a participação de stakeholders locais (muitos deles já tiveram seus problemas } \\
\text { pessoais resolvidos ou já acreditavam que não o seriam) e dos externos (não viam mais urgência e grande } \\
\text { necessidade de auxílio na comunidade). } \\
\text { * A associação, os líderes emergentes eleitos e os colaboradores duradouros persistem em causas mais } \\
\text { amplas e que demandam mais paciência e perseverança, como a construção do centro cultural com a sede da } \\
\text { associação, a construção de contenções no alto de imensas pedras da paisagem local, a desativação de uma } \\
\text { incineradora de resíduos tóxicos e a oferta de serviços de saúde, creche e escola no bairro. } \\
\text { * Ameniza-se a implicação e a mobilização dos stakeholders para colaborar. }\end{array}$ \\
\hline
\end{tabular}

Fonte: Elaborado pelos autores. 